\title{
Accumulation of Fe oxyhydroxides in the Peruvian oxygen deficient zone implies non-oxygen dependent Fe oxidation
}

\author{
Heller Maija Iris ${ }^{1}$, Lam Phoebe J. ${ }^{1,}{ }^{*}$, Moffett James W. ${ }^{2}$, Till Claire P. ${ }^{1}$, Lee Jong-Mi ${ }^{1}$, \\ Toner Brandy M. ${ }^{3}$, Marcus Matthew A. ${ }^{4}$
}

\author{
${ }^{1}$ Department of Ocean Sciences, University of California, Santa Cruz, CA, United States \\ ${ }^{2}$ Marine Environmental Biology, Department of Biological Sciences, University of Southern California, \\ Los Angeles, California 90089, United States \\ ${ }^{3}$ Department of Soil, Water, and Climate, University of Minnesota-Twin Cities, St. Paul, MN 55108 \\ United States \\ ${ }^{4}$ Advanced Light Source, Lawrence Berkeley National Laboratory, Berkeley, CA 94720, United States \\ * Corresponding author : Phoebe J. Lam, email address : pilam@ucsc.edu
}

\begin{abstract}
:
Oxygen minimum zones (OMZs) have been proposed to be an important source of dissolved iron (Fe) into the interior ocean. However, previous studies in OMZs have shown a sharp decrease in total dissolved $\mathrm{Fe}(\mathrm{dFe})$ and/or dissolved $\mathrm{Fe}(\mathrm{II})(\mathrm{dFe}(\mathrm{II}))$ concentrations at the shelf-break, despite constant temperature, salinity and continued lack of oxygen across the shelf-break. The loss of both total dFe and $\mathrm{dFe}$ (II) suggests a conversion of the dFe to particulate form, but studies that have coupled the reduction-oxidation (redox) speciation of both dissolved and particulate phases have not previously been done. Here we have measured the redox speciation and concentrations of both dissolved and particulate forms of Fe in samples collected during the U.S. GEOTRACES Eastern tropical Pacific Zonal Transect (EPZT) cruise in 2013 (GP16). This complete data set allows us to assess possible mechanisms for loss of dFe. We observed an offshore loss of dFe(II) within the oxygen deficient zone (ODZ), where dissolved oxygen is undetectable, accompanied by an increase in total particulate $\mathrm{Fe}$ (pFe). Total pFe concentrations were highest in the upper ODZ. X-ray absorption spectroscopy revealed that the pFe maximum was primarily in the $\mathrm{Fe}(\mathrm{III})$ form as $\mathrm{Fe}(\mathrm{III})$ oxyhydroxides. The remarkable similarity in the distributions of total particulate iron and nitrite suggests a role for nitrite in the oxidation of $\mathrm{dFe}(\mathrm{II})$ to $\mathrm{pFe}(\mathrm{III})$. We present a conceptual model for the rapid redox cycling of Fe that occurs in ODZs, despite the absence of oxygen.
\end{abstract}

Keywords : oxygen minimum zone, oxygen deficient zone, OMZ, ODZ, Fe redox cycling, synchrotron XAS 


\section{Introduction}

\subsection{Fe in seawater}

Iron $(\mathrm{Fe})$ is the most important trace metal in marine biogeochemistry due to its role as a key limiting element to primary productivity in many regions of the ocean (Boyd et al., 2007). Fe exists in two redox states in the environment, $\mathrm{Fe}(\mathrm{II})$ and $\mathrm{Fe}(\mathrm{III})$, with $\mathrm{Fe}(\mathrm{III})$ being the thermodynamically favored form in oxygenated seawater. However, dissolved Fe(III) (dFe(III)) becomes strongly hydrolyzed in seawater and forms Fe oxyhydroxides, which have a very low solubility.

Dissolved $\mathrm{Fe}(\mathrm{II})(\mathrm{dFe}(\mathrm{II}))$ is the more soluble form of Fe, but exists in ambient oxic seawater at extremely low concentrations because of rapid oxidation by its two main oxidants, oxygen $\left(\mathrm{O}_{2}\right)$ and hydrogen peroxide $\left(\mathrm{H}_{2} \mathrm{O}_{2}\right)$ (Millero and Sotolongo, 1989; Millero et al., 1987). In surface oxygenated seawater, $\mathrm{dFe}(\mathrm{II})$ is primarily generated by photochemical processes (Johnson et al., 1994), and is viewed as a reactive intermediate in Fe cycling.

$\mathrm{DFe}(\mathrm{II})$ exists at higher concentrations in oxygen depleted marine sediments where it is produced by dissimilatory Fe reducers that use Fe(III) to oxidize organic matter (Noffke et al., 2012). If the water overlying these sediments is oxygenated, reduced $\mathrm{dFe}$ (II) that diffuses from sediments is quickly oxidized by $\mathrm{O}_{2}$ or $\mathrm{H}_{2} \mathrm{O}_{2}$ to $\mathrm{dFe}(\mathrm{III})$, which forms colloidal and particulate $\mathrm{Fe}(\mathrm{III})(\mathrm{pFe}(\mathrm{III}))$ species. However, if the overlying waters are suboxic, the main oxidants for $\mathrm{Fe}(\mathrm{II})$ are absent, and consequently the $\mathrm{Fe}(\mathrm{II})$ redox state is more stable and can exist at nanomolar levels in the dissolved phase in oxygen deficient regions (Kondo and Moffett, 2013; Vedamati et al., 2014).

So-called oxygen minimum zones (OMZs) in the ocean are defined as regions that show distinct low oxygen layers at intermediate depths ( 100-1000 m) (Bopp et al., 2002; Stramma et al., 2008). Global OMZ volumes are predicted to increase with climate change, with some indications that this is already happening (Stramma et al., 2008). OMZs are generally found in waters that have been isolated from the atmosphere due to sluggish circulation, and thus have had their oxygen consumed by the oxidation of organic matter with no chance for renewal. Globally there are three major open ocean areas that exhibit this pattern- the eastern tropical Pacific, the eastern tropical Atlantic, and the Arabian Sea. Within these, the eastern tropical Pacific and Arabian Sea have "oxygen deficient zones" (ODZs), which are defined as areas in which dissolved oxygen is undetectable (Revsbech et al., 2009). 
OMZs have been proposed to be a source of Fe to the interior ocean through an "open marine iron shuttle" mechanism (Scholz et al., 2014b), in which elevated dFe(II) that is reductively mobilized from shelf sediments is exported into the ocean interior within the ODZ (Lyons and Severmann, 2006; Raiswell and Canfield, 2012; Scholz et al., 2014b). Scholz et al. (2014a) argue that Fe release from continental margin sediments is most effective in a narrow redox window where neither oxygen nor sulfide is present. The implications for this are that future deoxygenation in the Peru upwelling area might not result in increased Fe availability if the water column becomes sulfidic, but partial deoxygenation may enhance the Fe supply to the ocean from weaker OMZs.

The open marine Fe shuttle idea of Fe transport to the interior was based on a study of excess $\mathrm{Fe}$ (particulate $\mathrm{Fe}$ in sediments in excess of an expected lithogenic component) in surface sediments. It hypothesizes that $\mathrm{dFe}(\mathrm{II})$ should be high throughout the ODZ, and be removed at the oxycline below and at the offshore edge of the ODZ through oxidation and precipitation as particulate $\mathrm{Fe}(\mathrm{III})$ (pFe(III)).

However, in transects offshore from the broad Peruvian shelf, water column studies found that both total $\mathrm{dFe}$ and $\mathrm{dFe}(\mathrm{II})$ dropped off quickly with distance from the coast. Hong and Kester (1986) identified a chemical front about $30 \mathrm{~km}$ offshore in which both $\mathrm{dFe}(\mathrm{II})$ and total Fe dropped off sharply (from $\sim 30 \mathrm{nM}$ to $\sim 1 \mathrm{nM}$ ), showing that most Fe appeared to be trapped on the shelf. Likewise, both Bruland et al. (2005) and Vedamati et al. (2014) confirmed the sharp decrease in total $\mathrm{dFe}$ and/or $\mathrm{dFe}$ (II) concentrations at the shelf-break, despite constant temperature, salinity and continued lack of oxygen across the shelf-break.

The loss of both total $\mathrm{dFe}$ and $\mathrm{dFe}$ (II) suggests a conversion of the dFe to particulate form. The best evidence for this was a study by Landing and Bruland (1987), who measured total $\mathrm{dFe}$ as well as reactive (leachable in acetic acid) and total pFe at several stations in the Eastern Tropical North Pacific. In one offshore station, they found that the fraction of reactive $\mathrm{pFe}$ increased slightly in the ODZ. They hypothesized that reduced $\mathrm{dFe}$ was scavenged to a reactive particulate form, potentially low crystallinity oxyhydroxides, but they did not make redox measurements of dissolved or particulate Fe. Similarly, Vedamati et al. (2014) concluded that large lateral gradients observed in dissolved Fe across the shelf-slope break reflect production of $\mathrm{dFe}(\mathrm{II})$ by benthic processes on the shelf and $\mathrm{dFe}(\mathrm{II})$ removal by "oxidative scavenging", but they did not make measurements of the particulate phase. 
Our perspective on redox processes in ODZs has been transformed by new measurements of dissolved oxygen enabled by STOX sensors (Revsbech et al., 2009; Tiano et al., 2014), which reveal that dissolved $\mathrm{O}_{2}$ levels are less than $10 \mathrm{nM}$, much lower than the micromolar detection levels of conventional sensors or chemical assays. (Tiano et al., 2014) argued that with detection limits this low, these waters are "functionally anoxic". Indeed, it seems unlikely that oxygen could be poised at the low nanomolar level over hundreds of meters and is probably truly zero. Ulloa et al. (2012) went further and argued that ODZs with no STOX-detectable oxygen should be renamed Anoxic Marine Zones (AMZ). This suggests that we must look closely at linkages between Fe redox chemistry and the nitrogen cycle, since nitrate and nitrite are the only remaining plausible oxidants of Fe. Strong evidence for nitrate oxidation of $\mathrm{Fe}(\mathrm{II})$ derived from shelf sediments has been reported by (Scholz et al., 2016) who also reported genomic evidence for the presence of microbes containing nitrate reductases that have been shown in other systems to oxidize $\mathrm{Fe}(\mathrm{II})$.

The U.S. GEOTRACES Eastern tropical Pacific Zonal Transect (EPZT) cruise in 2013 (GP16) provided an opportunity to study, for the first time, Fe redox chemistry in both the dissolved and particulate phases in the water column on a transect extending to the westernmost limits of the ODZ. It also enabled us to place our findings in the context of other observations, including the distribution of other redox-reactive elements and radium-228 (Ra-228), which, like $\mathrm{Fe}(\mathrm{II})$, is also derived from marine sediments. This paper provides important insight into how processes studied by Scholz and coworkers in near bottom waters on the continental margin (Scholz et al., 2016) can be extended up into the water column and west to the offshore ODZ, and shows that rapid redox cycling of iron occurs in ODZs, despite the absence of oxygen.

\section{Study Area and sampling strategy}

The U.S. GEOTRACES Eastern Pacific Zonal Transect cruise (GEOTRACES cruise GP16) took place on the RV Thomas G. Thompson (TT-303) from 25 October to 20 December 2013 (Figure 1). The study area lies within the Humboldt Current system where southerly winds are known to cause an offshore Ekman transport and coastal upwelling. The Peru undercurrent, which is derived from the Equatorial Undercurrent, is in general known to be nutrient rich but low in oxygen (Kessler, 2006). The upwelling of this nutrient rich water is responsible for the high primary productivity at the Peruvian coast. Poor ventilation and the high 
oxygen demand are responsible for the OMZ in this region, which extends westward from the shelf from near surface to a depth of $\sim 1000 \mathrm{~m}$.

Three sampling systems were used to collect samples reported here: the 12-bottle Scripps Oceanographic Data Facility (ODF) rosette for non-contamination prone elements, the U.S. GEOTRACES sampling system of 24 Teflon-coated GO-FLO bottles (GTC Rosette) (Cutter and Bruland, 2012) for contamination prone elements (dFe(II) and dFe), and modified McLane WTS-LV in-situ pumps for particulate samples. High quality hydrographic parameters for oxygen, nitrite, nitrate measurements and shipboard data management were provided by the Scripps ODF for water from both rosettes. Nutrient analyses were performed on a Seal Analytical continuous flow Auto Analyzer 3. Nitrate was measured by first reducing it to nitrite using a cadmium reduction column. Nitrite was measured by standard colorimetric analysis of the red azo dye. Detection limits for $\mathrm{NO}_{3}{ }^{-}+\mathrm{NO}_{2}{ }^{-}$, and $\mathrm{NO}_{2}{ }^{-}$were each $0.02 \mu \mathrm{M}$. Dissolved oxygen analyses were performed using a whole-bottle modified Winkler titration method using an automated oxygen titrator. Detection limit was $0.90 \mu \mathrm{mo} / \mathrm{kg}$. Standard WOCE and CLIVAR protocols were used for all hydrographic measurements according to http://www.goship.org/HydroMan.html; further descriptions of analytical procedures, precisions, and calibration details are available at: http://cchdo.ucsd.edu/cruise/325020131025. Nitrite data from the ODF rosette cast(s) closest to the pump casts are used for comparisons to pump particles. Oxygen profiles are from the upcast of the SBE43, a polarographic membrane oxygen sensor, mounted on the ODF rosette, which was calibrated by Winkler titration noted above. The SBE43 typically has a detection limit of $1-2 \mu \mathrm{mol} \mathrm{O}_{2} / \mathrm{kg}$. Full resolution data for each system will be available at BCO-DMO (http://data.bco-dmo.org/jg/dir/BCO/GEOTRACES/EPZT/).

\subsection{Particulate sampling}

Sample collection was via dual-flow in-situ battery-powered pumps (modified McLane WTS-LV) suspended from a non-metallic hydrowire (Hytrel-coated Vectran). In-situ pump operations on GP16 were the same as used for GA03, the U.S. GEOTRACES North Atlantic Zonal Transect, described in (Ohnemus and Lam, 2015). Briefly, pumps operated for $4 \mathrm{~h}$ at a programmed rate of $8 \mathrm{~L} / \mathrm{min}$ in a dual-flowpath configuration that allowed for simultaneous collection of particles on two filter types: $51 \mu \mathrm{m}$ polyester prefilters were upstream of paired 0.8 $\mu \mathrm{m}$ polyethersulfone (PES) filters (Supor800, $142 \mathrm{~mm}$ diameter, $126 \mathrm{~mm}$ active diameter) on 
one flowpath, and also upstream of paired quartz fiber filters (Whatman QMA) on the other flowpath. All filters were acid-leached prior to use (Cutter et al., 2014) and loaded in miniMULVFS filter holders (Bishop et al., 2012). All sample handling was conducted in a self-built HEPA-filtered clean room bubble using trace-element handling techniques and acid-cleaned plastic equipment. Wedge-shaped subsamples of $51 \mu \mathrm{m}$ prefilters and paired Supor filters were cut using a ceramic rotary blade.

As soon as possible after the filter holders were brought on board, a small subsample (0.9 $\mathrm{cm}^{2}$, representing $\sim 3 \mathrm{~L}$ of equivalent volume filtered) of the Supor filter was cut and transferred into a glove box with a $\mathrm{N}_{2}$ atmosphere, sealed in a gas impermeable Mylar bag, and kept frozen to retard further oxidation of Fe in samples collected from the ODZ. This subsample was used for synchrotron analysis of $\mathrm{pFe}$ speciation.

The rest of the Supor filter was dried at room temperature on acid-leached polystyrene "eggcrate" grids in a HEPA-filtered flow hood, and subsequently stored in clear polyethylene clean room bags (KNF Flexpak). Samples from Stations 1-4 were lightly misted with Milli-Q water over gentle vacuum to reduce sea salt retention before drying; samples from Stations 5 and later were simply sucked down over gentle vacuum before drying. Comparisons of misted and unmisted samples from one station (Station 17) showed no significant difference in the concentrations of non-salt-dominated elements determined by ICP-MS.

Dipped blank filters were also deployed on each cast to allow seawater exposure to blank filters during deployment. These were complete filter sets that were processed identically to samples and thus functioned as process blanks (Bishop et al., 2012; Ohnemus and Lam, 2015). For Stations 1-21, dipped blank filter sets were loaded in mini-MULVFS filter holders that were not connected to the pump plumbing with a $0.2 \mu \mathrm{m}$ Supor prefilter to exclude particles.

\subsection{Seawater sampling}

Dissolved seawater samples were collected using the U.S. GEOTRACES sampling system of 24 Teflon-coated GO-FLO bottles (GTC Rosette) (Cutter and Bruland, 2012). At each station, the bottles were deployed open and tripped on ascent at $3 \mathrm{~m} / \mathrm{min}$. GO-FLOs were sampled in the GEOTRACES trace metal clean sampling van that contained HEPA-filtered air. GO-FLO bottles were pressurized to $\sim 0.4$ atm with $0.2 \mu \mathrm{m}$-filtered nitrogen (in contrast to previous GEOTRACES cruises where compressed air was used). Redox sensitive parameters 
were sampled first. Samples for total dissolved Fe were filtered using an Acropak-200 Supor capsule filter $(0.2 \mu \mathrm{m}$ pore size made of polyethersulfone). Before use, this filter had been filled

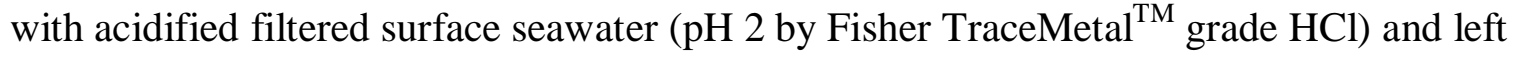
overnight to rinse. Before collecting any subsamples, at least $500 \mathrm{~mL}$ of seawater was passed through the filter. Sample bottles for $\mathrm{dFe}$ were rinsed three times with $10 \%$ sample volume before filling. Acropak filters were used for at most 3 casts before a new filter was used, and they were stored empty in a refrigerator while not in use.

For Fe(II) determination, samples were collected downstream of the Acropak or in some cases $0.2 \mu \mathrm{m}$ pore size Supor filters directly into polypropylene/polyethylene rubber-free syringes (Air-Tite, VWR) via luer fittings. They were stored in a bucket containing ice and analyzed in a clean van adjacent to the sampling van within 20 minutes.

\section{Analytical Methods}

\subsection{Dissolved Fe concentrations}

Samples for dFe were filtered into LDPE bottles that had been cleaned in accordance with the GEOTRACES cookbook (http://www.geotraces.org/images/stories/documents/intercalibration/Cookbook.pdf). Samples were acidified at sea with the equivalent of $4 \mathrm{~mL}$ of $6 \mathrm{~N}$ quartz-distilled $\mathrm{HCl}(\mathrm{q}-\mathrm{HCl})$ per liter of seawater (to $\mathrm{pH}$ 1.7-1.8), and were left acidified for at least several months prior to analysis in the laboratory. Dissolved Fe was analyzed using an adaptation of Biller and Bruland (2012) as described in Parker et al. (2016). Briefly, this method involves UV irradiating the samples, preconcentrating the metals of interest by loading seawater at $\mathrm{pH} 6.0$ onto a column of Nobiaschelate PA-1 resin and eluting with $1 \mathrm{~N} \mathrm{q}-\mathrm{HNO}_{3}$, and analyzing the eluent on the ThermoElement High Resolution XR Inductively Coupled Plasma Mass Spectrometer at UC Santa Cruz. Iron was analyzed in medium resolution in counting mode.

Two different blanks were determined and subtracted from sample values (Parker et al. 2016). Column blanks were analyzed each ICP-MS run by loading only a small volume ( 1 mL) of low-metal seawater and otherwise pre-concentrating and analyzing on the ICP-MS as usual. The column blanks serve to alert us to any differences in the blank between columns and also account for the blank of the analytical process, except from the reagents in the samples. For that 
we also analyze reagent blanks each ICP-MS run by preconcentrating low-metal seawater twice with usual concentrations of reagents and twice with double the reagents, and subtracting the resulting concentrations. The column blanks were used to calculate the detection limit (defined as three times the standard deviation of the blank), which was $0.038 \mathrm{nM}(\mathrm{n}=34)$ during analysis of these samples.

As a quality control, SAFe reference samples were analyzed in the same preconcentration and ICP-MS runs as the EPZT samples. Our analysis resulted in values for SAFe S of $0.095 \pm$ $0.014 \mathrm{nmol} / \mathrm{kg}(\mathrm{n}=12)$, for SAFe D2 of $0.965 \pm 0.089 \mathrm{nmol} / \mathrm{kg}(\mathrm{n}=10)$, and for SAFe D1 of $0.68 \pm 0.07(n=6)$. These values are within one standard deviation of the May 2013 consensus values of $0.093 \pm 0.008,0.933 \pm 0.023$, and $0.67 \pm 0.04 \mathrm{nmol} / \mathrm{kg}$, respectively.

\subsection{Dissolved Fe(II) concentrations}

Dissolved Fe(II) concentrations were determined using an automated flow injection analysis system (FeLume II Waterville Analytical) employing a luminol chemiluminescence based detection system (King et al., 1995). Luminol, prepared in 18.2 M $\Omega$ Milli-Q water and buffered to $\sim \mathrm{pH}-10.3$ with ammonia $\left(\mathrm{Optima}^{\mathrm{TM}}\right)$, reacts with an $\mathrm{Fe}(\mathrm{II})$-containing solution, resulting in luminol oxidation with concurrent chemiluminescent emission (Croot and Laan, 2002; Rose and Waite, 2001). The FeLume was fitted with a standard quartz flow cell and a Hamamatsu HC135 photon counter configured with the following settings: flow rate: $2.5 \mathrm{~mL}$ per minute; photon counter integration time: 200 milliseconds; load time: 20 - 40 seconds. The mixing and reaction occur in a spiral flow cell positioned in front of a photomultiplier tube. The sample and luminol reagent was continually mixed in the flow cell by omitting the injection valve (Hopkinson and Barbeau, 2007; Rose and Waite, 2001; Roy et al., 2008). Once the signal was in steady-state, the mean of the last 50 data points was used to determine the signal.

$\mathrm{Fe}(\mathrm{II})$ was quantified by standard additions of Fe(II) (typically 0.05, 0.1, 0.5 and 1 $\mathrm{nM}$ ) to the samples of surface seawater (stored in the dark several days) or deep, oxygenated water with low initial signals. A $0.01 \mathrm{M} \mathrm{Fe}(\mathrm{II})$ stock solution was prepared with ferrous sulfate (Sigma) in $0.2 \mathrm{M} \mathrm{HCl}$. A working Fe(II) standard solution (100 nM) was prepared daily. Detection limits were determined for aged surface samples where ferrous Fe was negligible 
based on a standard 3 $\sigma$ evaluation of the baseline signal (Kondo and Moffett, 2013; Moffett et al., 2007). This led to a detection limit of $14 \mathrm{pmol} / \mathrm{L}$.

\subsection{Particulate trace metal concentrations}

Filter subsamples of the top Supor filter representing 6-12\% of the filter area (about 2550 L equivalent volume filtered) were digested for determination of total particulate trace metal concentrations in the $0.8-51 \mu \mathrm{m}$ size fraction. Digestion followed the two-step method (Ohnemus et al., 2014; Ohnemus and Lam, 2015), in which the polyethersulfone (PES) filter is first completely dissolved in the highly oxidizing Piranha reagent, which is 3 parts concentrated (18.4 M, $98 \%$ ) sulfuric acid to 1 part concentrated (30-32\%) hydrogen peroxide $\left(\mathrm{H}_{2} \mathrm{O}_{2}\right)$, and then lithogenic material is dissolved in a strong acid mixture containing $4 \mathrm{M}$ each of $\mathrm{HNO}_{3}, \mathrm{HCl}$, and HF (Ohnemus et al., 2014). All reagents were Seastar Baseline-grade unless otherwise mentioned. All digestions and PFA vial cleaning were conducted in a HEPA-filtered venting fumehood at University of California, Santa Cruz (UCSC), within a HEPA-filtered room.

Slight modifications were made to minimize reagent usage in the Piranha step to accelerate the dry-down process. Filter subsamples were cut into small pieces using a ceramic blade before placing in $15 \mathrm{~mL}$ PFA vials (Savillex) to ensure that the entire filter material was covered by the digestion solution. Initially, $800 \mu \mathrm{L}$ concentrated $\mathrm{H}_{2} \mathrm{SO}_{4}$ was added to the vial containing the cut filter pieces, along with $20 \mu \mathrm{L}$ of a rhodium (Rh) spike (final concentration 1 $\mathrm{ppb})$ to monitor potential loss during the digestion process. The vials were heated at $150{ }^{\circ} \mathrm{C}$ for $1.5 \mathrm{~h}$ with the lids on loosely. The hotplate was then turned off, the lids taken off, and each vial was gently swirled. After $\sim 5$ minutes, $265 \mu \mathrm{L}$ concentrated $\mathrm{H}_{2} \mathrm{O}_{2}$ was incrementally added to each vial, generating the Piranha solution. After the first addition of $\mathrm{H}_{2} \mathrm{O}_{2}$, the hotplates were turned on again at $100{ }^{\circ} \mathrm{C}$ followed by a second $265 \mu \mathrm{L} \mathrm{H}_{2} \mathrm{O}_{2}$ addition. The temperature was then increased to $150^{\circ} \mathrm{C}$ for 30 minutes, followed by a third addition of $265 \mu \mathrm{L} \mathrm{H}_{2} \mathrm{O}_{2}$. After each addition of $\mathrm{H}_{2} \mathrm{O}_{2}$, the lids were placed loosely atop the vials to allow a good reactivity of the Piranha solution while also preventing loss associated with spatter.

Depending on the particle load and composition on each filter, three $\mathrm{H}_{2} \mathrm{O}_{2}$ additions resulted in liquid ranging from colorless to dark brown, with occasionally undissolved filter pieces. In samples that were not colorless, additional smaller $\mathrm{H}_{2} \mathrm{O}_{2}$ volumes $(50-150 \mu \mathrm{L})$ were added and the vials swirled until subsequent $\mathrm{H}_{2} \mathrm{O}_{2}$ additions no longer generated a fizzing 
solution and a clear solution was attained. Vial blanks (reagents only) and dipped filter blanks underwent the same procedures as the samples. After all solutions were clear, lids were removed, and vials and inverted lids were carefully dried, first at $200{ }^{\circ} \mathrm{C}$, then $220{ }^{\circ} \mathrm{C}$, and finally $235{ }^{\circ} \mathrm{C}$ for several hours until only a small droplet remained.

After the PES matrix was oxidized by the Piranha procedure, a mineral acid total digestion was performed on the remaining particulate material (Ohnemus et al., 2014; Ohnemus and Lam, 2015). Briefly, $2 \mathrm{~mL}$ of a freshly prepared mixture of $\mathrm{HNO}_{3}, \mathrm{HCl}$, and $\mathrm{HF}$ (4 $\mathrm{M}$ each) was refluxed for 4 hours at $135^{\circ} \mathrm{C}$, then dried down for several hours at $110^{\circ} \mathrm{C}$.

The final remaining droplet was brought up in $2 \mathrm{~mL} 5 \% \mathrm{HNO}_{3}$ with 1 ppb In as an internal standard. The final digest solution was diluted gravimetrically $5 \mathrm{x}$ and $20 \mathrm{x}$ using the same $5 \% \mathrm{HNO}_{3} / 1 \mathrm{ppb}$ In solution and analyzed by high-resolution Inductively Coupled Mass Spectrometry (HR-ICP-MS) using an Element-XR ICP-MS (Thermo Scientific) with SC-FAST (Elemental Scientific) sample introduction system and PC3 Peltier cooled quartz cyclonic spray chamber in the UCSC Plasma Analytical Facility. Instrument drift and matrix effects were corrected using the internal 1ppb In standard and monitored using a mixed element run standard. Concentrations were determined using external standard curves of mixed trace elements standards. The median dipped blank (15.0 nmol Fe/filter) was subtracted from all samples. The detection limit (58.7 nmol Fe/filter) was defined as three times the standard deviation (19.6 nmol Fe/filter) of 45 dipped blank filters, which translates to an approximate concentration detection limit for $\mathrm{pFe}$ of $0.14 \mathrm{nM}$ given typical volumes filtered. The resulting Fe data for the eastern third of the transect is discussed in this present manuscript. Other particulate trace metal data will be discussed in subsequent manuscripts.

The same digestion and analysis procedure was regularly applied to approximately $15 \mathrm{mg}$ each of two certified reference materials: BCR-414, a freshwater plankton, and PACS-2, a coastal marine sediment. Mean \pm standard deviation of recoveries for Fe were $106 \pm 13 \%$ for BCR-414 and $83 \pm 6 \%$ for PACS-2.

\subsection{Particulate iron speciation}

We conducted a series of synchrotron-based X-ray measurements of the $0.8-51 \mu \mathrm{m}$ particulate size fraction collected by in-situ filtration during 3 visits to the Advanced Light Source (ALS) 
microprobe beamline 10.3.2 in Berkeley, CA, USA (Marcus et al., 2004) in 2014 and 2015. Beamline 10.3.2 is a bending magnet microprobe beamline that uses a silicon ( $\mathrm{Si}(111))$ crystal monochromator to create a monochromatic beam with a 2-15 $\mu \mathrm{m}$ spot size. All measurements were made in fluorescence mode using a Canberra 7-element UltraLEGe solid-state Ge detector. For all measurements, the monochromator was calibrated to put the inflection point for Fe metal at $7110.75 \mathrm{eV}$.

All samples were mounted dry in a manner that limited sample exposure to oxygen during irradiation by X-ray beam (Toner et al., 2016; Zeng et al., 2013). Briefly, all sample preparation was conducted in a portable Captair pyramid glove bag under argon (Ar) atmosphere. Samples, which were stored under Ar or $\mathrm{N}_{2}$ atmosphere at $-20^{\circ} \mathrm{C}$, were mounted and sealed between two layers of X-ray transparent, gas-impermeable Mylar film. The X-ray analysis was then performed at ambient atmosphere.

\subsubsection{Chemical species mapping}

Chemical species maps were created to determine the redox speciation of particulate $\mathrm{Fe}$ in our samples. X-Ray Fluorescence (XRF) maps were collected at four energies around the Fe Kedge (Table 1). Typically, a randomly chosen $1000 \mu \mathrm{m}$ x $250 \mu \mathrm{m}$ area was mapped using a beam spot size of $5 \mu \mathrm{m}$, a pixel size of $4 \mu \mathrm{m}$, and a dwell time of $100 \mathrm{~ms}$. The mapping area represented an equivalent volume filtered of $\sim 8 \mathrm{~mL}$. Differences in sample to detector distances or number of functioning detector elements between beamline visits were accounted for using a thin-film XRF standard (Micromatter ${ }^{\mathrm{TM}}$, Vancouver, Canada) for Fe $\left(43.9 \mu \mathrm{g} \mathrm{Fe} / \mathrm{cm}^{2}\right)$, which was mapped at the same beamline settings as the samples.

The pre-edge $(7100 \mathrm{eV})$ and post-edge $(7296 \mathrm{eV})$ energies to determine the background and total FeK $\alpha$ counts, respectively, were identical for all beamline visits. The two intermediate energies used to distinguish between Fe species varied slightly between beamline visits (Table 1) as we optimized the analysis over the beamline visits with the help of an error minimization and analysis program available at the beamline (Lam et al., 2012; Marcus, 2010). We chose the following three Fe species as reference input spectra for calculating chemical species maps: pyrite to represent $\mathrm{Fe}$ sulfides, $\mathrm{FeSO}_{4}$ to represent $\mathrm{Fe}(\mathrm{II})$-containing species, and a hydrous ferric oxide ("HFO-Fe4-P4") to represent Fe(III) species. The XANES spectra of both $\mathrm{FeSO}_{4}$ and HFO-Fe4-P4 have very little structure post edge, and were chosen specifically to represent 
generic Fe(II)- and Fe(III)-containing species, respectively. The chemical species mapping calculation partitions total apparent Fe counts at $7296 \mathrm{eV}$ into four channels: background counts from scatter and non-Fe sources, Fe sulfides, Fe(II) species, and Fe(III) species. The proportion of $\mathrm{Fe}$ attributed to each $\mathrm{Fe}$ species (Fe sulfide, $\mathrm{Fe}(\mathrm{II})$, and $\mathrm{Fe}(\mathrm{III})$ ) was determined as the ratio of counts in each Fe species channel to the sum of the three Fe species. Total pFe concentrations were calculated from background-corrected counts in the $7296 \mathrm{eV}$ channel using the Fe standard to $\mu \mathrm{g} \mathrm{Fe} / \mathrm{cm}^{2}$ and dividing by the equivalent volume filtered through the map area.

Concentrations of $\mathrm{pFe}$ species were calculated from total $\mathrm{pFe}$ and the proportion of $\mathrm{Fe}$ attributed to each Fe species.

\subsubsection{X-ray Absorption Spectroscopy}

The attribution of Fe species from the chemical species mapping was verified by collecting multiple Fe K-edge extended $\mu$-X-ray Absorption Near-Edge Structure ( $\mu$-XANES) spectra for each sample. A reproducible glitch in the monochromator at $7263.8 \mathrm{eV}$ was used as an internal energy calibration for each extended XANES spectrum. All Fe K-edge $\mu$-XANES data were collected from 7010-7414 eV in quick-XAS mode ( 45 seconds/sweep), with the finest energy resolution $(0.5 \mathrm{eV})$ in the XANES region $(7095-7140 \mathrm{eV})$ and near the monochromator glitch (7261-7271 eV), and coarser step sizes otherwise (1 eV between 7010-7095 eV and 7140-7261 $\mathrm{eV}$, and $3 \mathrm{eV}$ between 7271-7414 eV). Sweeps were repeated until signal to noise was acceptable: typically 20-30 sweeps for each spot. For each spectrum, we corrected for detector deadtime and energy drift, removed the pre-edge background, and normalized the spectrum based on the extended region XANES region $(\sim 7250-7350 \mathrm{eV})$. Normalized XANES spectra were fit using linear combination fitting of a library of extended Fe K-edge XANES spectra from $58 \mathrm{Fe}$ reference minerals that represented a range of $\mathrm{Fe}(\mathrm{II})$ and $\mathrm{Fe}(\mathrm{III})$ containing oxides, silicates, carbonates, and sulfides (Table 2).

The identity of Fe(III) species in the ODZ was determined using Extended X-ray Absorption Fine Structure (EXAFS) spectroscopy. EXAFS data were collected in quick-XAS fluorescence mode ( 1 minute/sweep) from 7000-7800 eV (to $\mathrm{k}=13$ ). More than 200 sweeps were collected for each spot for adequate signal to noise in the EXAFS region. Sweeps were averaged, deadtime corrected, and pre-edges were removed. $\mathrm{E}_{0}$ was determined as the energy halfway up the edge step, and was $7123 \mathrm{eV}$ for both samples. A cubic spline fit between $7131-7765 \mathrm{eV}(\mathrm{k}=$ 
1.5-13) was used to remove the background and extract the EXAFS. The $\mathrm{k}^{3}$-weighted EXAFS were fit by linear combination fitting of a library of EXAFS spectra of Fe(III) species (Table 2). The ten best fits were examined to assess the robustness of the species appearing in the fits.

There was no evidence of beam damage over the course of the multiple XANES or EXAFS sweeps. For all XANES and EXAFS, the incident beam spot size was adjusted to maximize Fe count rate without exceeding a total fluorescence count rate of 300,000 cps, and was typically 12 $\mu \mathrm{m} x 4 \mu \mathrm{m}(\mathrm{HxV})$. All synchrotron data processing was performed using LabView-based software available at beamline 10.3.2 (https://sites.google.com/a/lbl.gov/microxas-lblgov/software).

\subsection{Error estimates and corrections for particulate iron chemical species}

We considered three sources of error in the quantitative estimate of $\mathrm{pFe}$ species by chemical species mapping: 1) error that arises from mapping a small area of the sample, referred to as distribution error, 2) error due to differences in the beamline between visits, referred to as beamline error, and 3) error that arises from the chemical mapping parameters chosen, such as the energies used for mapping and the choice of reference Fe species used to calculate the chemical species map. We assessed the last source of error by taking multiple spot XANES measurements to confirm the categorization by the mapping calculation, discussed further in sections 3.4.2 and 4.3.2. We estimated the distribution error by mapping two randomly selected areas of the filter during a single visit (GT2276 during the 201404 visit—see Table 3). We found a relative standard deviation for the distribution $\left(R S D_{\text {dist }}\right)$ of $9 \%, 3 \%, 0.1 \%$, and $4 \%$ for $\% \mathrm{Fe}(\mathrm{II}), \% \mathrm{Fe}(\mathrm{III}), \% \mathrm{Fe}-$ sulfide, and total Fe, respectively (Table 4$)$. We assessed the beamline error by mapping the same sample at two beamline visits and comparing Fe species determinations. When we did this for a sample mapped during the 201404 and 201409 visits (GT2326 - see Table 3), we found $R S D_{2014 b e a m}$ of $16 \%, 7 \%, 8 \%$, and $11 \%$ for $\% \mathrm{Fe}(\mathrm{II})$, $\% \mathrm{Fe}(\mathrm{IHI}), \% \mathrm{Fe}$-sulfide, and total Fe, respectively (Table 4). When we applied this approach to a sample measured in the 201409 and 201510 beamline visits (GT2443 - see Table 3), however, we found a much greater difference $\left(R S D_{2014-15 \text { beam }}\right.$ of 38-63 \%--Table 4$)$. All samples run in 2015 had anomalously high proportions of reduced Fe compared to samples run in 2014. In 2015, there were problems with a hydrocarbon residue coating on the vertical collimator. The flare coming off this mirror increased the divergence onto the monochromator, yielding a 
degraded energy resolution that resulted in a vertical beam flare, which is erroneously detected as X-ray absorption at lower energies and thus interpreted as the presence of reduced Fe. This is clearly visualized by plotting the proportion of $\mathrm{Fe}(\mathrm{III}), \mathrm{Fe}(\mathrm{II})$, and Fe-sulfide species for Station 5, which were mostly collected in 2015, compared to Stations 2 and 3, which were collected in 2014 (Figure 2).

A beam flare issue would also appear in XANES spectra as a shift to lower energies, so using reference XANES spectra collected under the same beamline conditions in the chemical map calculations should account for the artifact. To correct for the flare-induced erroneous attribution of Fe to reduced species in 2015, we used a XANES spectrum taken from a sample in 2015 that appeared the most oxidized as an approximation of what a pure Fe(III) reference XANES would look like with the beam flare. The chemical map calculation was made with this oxidized sample XANES spectrum instead of HFO as an Fe(III) reference.

This approach yielded Fe species profiles that were shifted towards more oxidized Fe throughout the water column compared to the raw profiles (Figure 2), and closer to the repeat sample (GT2443 from Station 5, 200m) that was also run in 2014. Using the repeat sample, the relative standard deviations between the 2014 and corrected 2015 data, $R S D_{2015 \text { corr } 1}$ (16\% Fe(II), $9 \% \mathrm{Fe}(\mathrm{III}), 27 \% \mathrm{Fe}$ sulfide) were much more similar to the typical variability encountered between beamline visits in 2014 (RSD 2014 beam $)$ (Table 4).

\section{Results}

\subsection{Oxygen and nitrite distribution}

The stations reported here are the 11 stations sampled along $12^{\circ} \mathrm{S}$ closest to the Peruvian shelf (Figure 1), which all showed a distinct ODZ (Figures 3, 4). At Stations 2 and 3 on the shelf, oxygen decreased from the surface until the detection limit was reached around $70 \mathrm{~m}$ and $35 \mathrm{~m}$, respectively (Figures 3, 4). At these 2 stations the ODZ reached the ocean floor (122 $\mathrm{m}$ and $180 \mathrm{~m}$ ). The upper depth of the ODZ was around $65 \mathrm{~m}$ at Station 4, deepening westward to $200 \mathrm{~m}$ by Station 11, while the lower bound of the ODZ shoaled westward from about $500 \mathrm{~m}$ at Station 4 to about $240 \mathrm{~m}$ by Station 11. Oxygen levels were similar to those previously reported for the region by Hong and Kester (1986), Noffke et al. (2012), Chever et al. (2015), and Vedamati et al. (2014). The standard methods to determine oxygen concentrations used here have detection limits of 1-2 $\mu \mathrm{M}$ and the nominal concentrations of oxygen within the ODZ were 
at or below this value. However, for reasons outlined previously (Tiano et al., 2014; Ulloa et al., 2012), we assume oxygen concentrations are low enough that it is not important as an oxidant, if not completely absent.

Nitrite concentrations were highest near the shelf, reaching $\sim 10 \mu \mathrm{M}$ at Stations 3,4 , and 5 (Figures 3,4), and typically peaked in the upper part of the ODZ, with the depth of the peak deepening westward from $69 \mathrm{~m}$ at Station 2 closest to the coast to $220 \mathrm{~m}$ at Station 11 furthest offshore, following the upper boundary of the ODZ (Figures 3, 4). At some stations (Stations 3, $5,1,7$ ), there was more than one nitrite maximum within the ODZ (Figure 4). As the top of the ODZ deepened westward, a distinct primary nitrite peak above the ODZ was sometimes also noticeable (e.g., $0.5 \mu \mathrm{M}$ at $110 \mathrm{~m}$ at Station 11). Nitrite was undetectable below the ODZ (Figures 3, 4).

\subsection{Distributions of dissolved Fe, dissolved Fe(II) and total pFe concentrations}

$\mathrm{DFe}(\mathrm{II})$ concentrations were highest on the shelf, decreasing offshore (Figure 3D). Vertical profiles of $\mathrm{dFe}(\mathrm{II})$ (Figure 4) were generally characterized by maxima between 100-400 $\mathrm{m}$ within the ODZ, with the highest concentrations found in near-bottom samples on the shelfslope including $25.6 \mathrm{nM}$ at $108 \mathrm{~m}($ bottom $=122 \mathrm{~m})$ at Station 2 and $8.1 \mathrm{nM}$ at $170 \mathrm{~m}($ bottom = $180 \mathrm{~m})$ at Station 3. Elevated $(\geq 1 \mathrm{nM})$ concentrations of $\mathrm{dFe}(\mathrm{II})$ were generally confined to Stations 2-5 on the shelf/slope. DFe(II) remained detectable within the ODZ west of Station 5, primarily within the secondary nitrite maximum until that feature disappeared west of Station 11.

Concentrations of total dissolved $\mathrm{Fe}(\mathrm{dFe})$ were also highest on the shelf and decreased offshore, with a sharp drop west (offshore) of Station 5, as for dFe(II). West of Station 5, however, the vertical distribution of $\mathrm{dFe}$ (Figure $3 \mathrm{~F}$ ) did not exhibit a maximum in the ODZ, but rather increased with depth below the ODZ. Within the upper part of the ODZ, dFe(II) generally accounted for a majority of the total dissolved Fe, but was a very small percentage in the lower part of the ODZ and below the ODZ.

Concentrations of total $\mathrm{pFe}$ were generally highest near the shelf and slope stations east of Station 1 (Figures 3,4). Vertical profiles of pFe in the upper $500 \mathrm{~m}$ were characterized by a near-surface minimum, and a local maximum in the upper part of the ODZ. The near-surface $(<50 \mathrm{~m})$ minima ranged from $1.2 \pm 0.09 \mathrm{nM}$ at $38 \mathrm{~m}$ at Station 2 closest to the coast to below the detection limit $(<0.14 \mathrm{nM})$ west of Station 7 . The pFe maxima in the upper ODZ deepened 
westward, and ranged from a maximum of $10.9 \pm 0.59 \mathrm{nM}$ at $70 \mathrm{~m}$ at Station 2 closest to the coast to $0.4 \pm 0.05 \mathrm{nM}$ at $225 \mathrm{~m}$ at Station 11 offshore. The maximum concentrations of $\mathrm{pFe}$ in the ODZ remained relatively high ( $>3 \mathrm{nM}$ ) from Station 2 west through Station 1, before decreasing more quickly westward starting at Station 7.

\subsection{Synchrotron analysis of $\mathrm{pFe}$ speciation}

\subsubsection{Redox state of $\mathrm{pFe}$ in the ODZ}

Synchrotron-based chemical species maps of 1-51 $\mu \mathrm{m}$ particles from the upper $600 \mathrm{~m}$ of three coastal stations (Stations 2, 3,5) show that the samples in the $\mathrm{pFe}$ maxima were dominated by Fe(III) (blue color in Figure 5). Quantification of the intensities in each Fe species channel show that the percentage of total $\mathrm{pFe}$ as $\mathrm{Fe}(\mathrm{III}), \mathrm{Fe}(\mathrm{II})$, and Fe-sulfide exhibited similar profiles at the three stations. All three stations were characterized by a minimum in \% Fe(III) near surface at each of the three stations where total $\mathrm{pFe}$ was very low (Figures 2,6 ), increasing with depth until a maximum of up to $80 \% \mathrm{Fe}$ (III) was reached between $50 \mathrm{~m}-150 \mathrm{~m}$ (Figure 2).

Total $\mathrm{pFe}$ determined by XRF was generally comparable to total $\mathrm{pFe}$ determined by ICPMS (Figure 6). The sample areas from which XRF pFe were determined represented only about $8 \mathrm{~mL}$ of equivalent volume filtered, compared to 25-50 L for ICP-MS subsamples, so the ICPMS-derived pFe are expected to be more accurate.

All $\mathrm{pFe}$ species were low in near surface waters, and increased in concentration from the surface into the upper part of the ODZ (Figure 6). In the euphotic zone, the particulate Fe:P ratio approached typical stoichiometric ratios found in phytoplankton (Figure S1), suggesting that a significant fraction of $\mathrm{pFe}$ there may have been biologically-bound. Below the euphotic zone, particulate Fe:P ratios greatly exceed phytoplankton ratios.

Overall, Fe-sulfides were a minor component of $\mathrm{pFe}$ in the water column (Figure 6), and were the greatest fraction of total $\mathrm{pFe}$ (up to $17 \%$ ) above $60 \mathrm{~m}$ in the euphotic zone (Figure 2). Particulate acid volatile sulfides (AVS) were measured on separate pump subsamples and only detected in the euphotic zone (Ohnemus et al., 2016), suggesting a phytoplankton source for the AVS and perhaps the Fe-sulfides detected here in the euphotic zone. Pyrite particles are identifiable in chemical maps as intense, small red spots, and were occasionally detected below the euphotic zone at Stations $2(70 \mathrm{~m}), 3(170 \mathrm{~m})$, and $5(120 \mathrm{~m})$ (Figure 5) and confirmed by their distinctive XANES spectra (Figure 7). The abundance of distinct pyrite particles was very 
low, however, and they may have derived from resuspended and laterally-transported pyrite formed in sediments (cf. Lam et al., 2012).

The majority of euphotic zone pFe was categorized as Fe(II), and may represent biologically-bound Fe, given the Fe:P ratios at these depths. Below the euphotic zone, most of the total $\mathrm{pFe}$, including the increase in the upper ODZ, was comprised of $\mathrm{pFe}(\mathrm{III})$. Particulate Fe:Al exceed crustal ratios throughout the upper $500 \mathrm{~m}$ (Figures S2). Particulate Fe below the euphotic zone is therefore unlikely to be dominated by either biologically bound or silicatebound components.

\subsubsection{Speciation of $\mathrm{pFe}$}

We performed X-ray Absorption Near-Edge Structure (XANES) spectroscopy on multiple Fe-rich spots from each chemical species map to confirm the categorization of pFe redox state by the chemical mapping procedure, and also to further determine the chemical speciation of the $\mathrm{pFe}$ at a higher level of detail than is provided by the chemical species mapping. Fe K-edge $\mu$-XANES spectra of multiple spots from samples from the depth of the ODZ pFe maximum (Station 2-70 m, n = 9; Station 3-90 m, n = 9; Station 5-120 m, n = 15) were compared to the XANES spectra of model Fe species (HFO-Fe4-P4 for $\mathrm{Fe}(\mathrm{III}), \mathrm{FeSO}_{4}$ for $\mathrm{Fe}(\mathrm{II})$, and pyrite for Fe-sulfide) and used to calculate the chemical species maps (Figure 7). With the exception of two spectra from Station 5 that appear significantly chemically reduced, the 31 other XANES spectra plotted close to the Fe(III) model spectrum, confirming the dominance of $\mathrm{Fe}(\mathrm{III})$ predicted by the chemical species map at the ODZ $\mathrm{pFe}$ maximum. Indeed, a composite model Fe XANES spectrum that was a $25 \% / 75 \%$ mixture of the $\mathrm{Fe}(\mathrm{II})$ and $\mathrm{Fe}(\mathrm{III})$ model species, which was the overall oxidation state predicted by the chemical species maps at the ODZ pFe maximum (Figure 2), is an excellent approximation of the ensemble of sample XANES spectra (Figure 7). The two spectra that appear chemically reduced were identified in the chemical species map as Fe particles having significant pyrite and $\mathrm{Fe}(\mathrm{II})$, consistent with their XANES spectra (Figure 7).

Because the detailed identification of poorly crystalline Fe(III) species is difficult by XANES, we chose two Fe(III)-rich spots on samples within the ODZ to conduct EXAFS analysis, one from Station 2 at $108 \mathrm{~m}$, which was near bottom (bottom depth $=122 \mathrm{~m}$ ), and one from Station 5 at $200 \mathrm{~m}$ (bottom depth $=2072 \mathrm{~m}$ ) (Figure 8). Both samples were well within the 
ODZ, and many tens of meters away from the oxycline, making it unlikely that these samples were exposed to oxygen in situ. The EXAFS of the Fe(III)-rich spot from Station 5 at $200 \mathrm{~m}$ was well fit with two Fe(III) oxyhydroxides: $34 \%$ lepidocrocite $(\gamma-\mathrm{FeOOH})$ and $74 \%$ feroxyhyte ( $\delta$ '-FeOOH). The EXAFS of the Fe(III)-rich spot from Station 2 at $108 \mathrm{~m}$ (near-bottom) was well fit with two Fe(III) oxyhydroxides (20\% lepidocrocite and $25 \%$ poorly crystalline hydrous ferric oxide (HFO), and $46 \% \mathrm{Fe}(\mathrm{III})$-containing clay (illite).

\section{Discussion}

\subsection{Sources of $\mathrm{dFe}(\mathrm{II})$ in the $\mathrm{ODZ}$}

While there have been episodic observations of sulfide accumulation in the Eastern Tropical Pacific ODZ, especially on the shelf (Bruchert et al., 2003; Dugdale et al., 1977), and a "cryptic sulfur cycle" in which sulfide production and sulfate reduction are tightly coupled has been proposed (Canfield et al., 2010), the redox potential of the Eastern Tropical Pacific is generally not low enough to be sulfidic. Measurement of multiple redox-sensitive trace elements (iodine (I), manganese (Mn), chromium (Cr), selenium (Se), and iron (Fe)) in oxygen deficient waters of the Eastern Tropical North Pacific suggested the redox potential was set by the nitratenitrite, $\mathrm{Cr}(\mathrm{VI})$ - $\mathrm{Cr}(\mathrm{III})$, and selenate-selenite redox couples, well above that required for in-situ dissimilatory Fe or sulfate reduction (Rue et al., 1997). Similar measurements during the EPZT cruise also indicate that the bulk water column redox potential was not low enough for in-situ $\mathrm{Fe}(\mathrm{III})$ reduction (Cutter and Nielsdottir, 2014). Observed dFe(II) in the ODZ water column may have originated from sediments, where the redox potential is low enough for benthic Fe reduction, and transported along isopycnal surfaces. Indeed, the $26.1-26.55 \mathrm{~kg} / \mathrm{m}^{3}$ potential density surface connects shelf sediments to the elevated dFe(II) features in the upper ODZ ( $c f$. Figure 3). A sedimentary source of dFe(II) is supported by two lines of evidence. First, light Fe isotopic values, a tracer of dissimilatory Fe(III) reduction, were observed in the leachable particulate Fe pools in the ODZ zone of the EPZT cruise (Marsay and John, 2014), as well as in shelf waters in a previous study along the Peruvian upwelling coast (Chever et al., 2015). Second, measurements of Ra-228, a tracer of recent ( $<10$ years) sedimentary contact, revealed surface plumes of water with a strong shelf input that decline sharply above the oxycline, but are still elevated above background at the depths of the dFe(II) features (Sanial et al., accepted). Laterally-transported shelf sources of dFe(II) may also be supplemented by in-situ sources of 
$\mathrm{dFe}(\mathrm{II})$. Although the bulk redox potential is not low enough for in-situ Fe(III) reduction, dissimilatory in-situ $\mathrm{Fe}(\mathrm{III})$ reduction could potentially occur in microenvironments (c.f. Canfield et al., 2010). Moffett et al. (2007) also hypothesized that in situ reduction of Fe(III) to $\mathrm{Fe}(\mathrm{II})$ might occur as part of an assimilatory Fe acquisition strategy. Finally, as we will further discuss in section 5.3, some $\mathrm{dFe}(\mathrm{II})$ could also be produced in-situ from the remineralization of particulate organic matter.

\subsection{Conversion of $\mathrm{dFe}(\mathrm{II})$ to $\mathrm{pFe}$ in the ODZ of the EPZT}

In the upper ODZ of the EPZT (defined here as the $26.1-26.55 \mathrm{~kg} / \mathrm{m}^{3}$ potential density surfaces), depth-averaged dissolved Fe(II) concentrations drop off more quickly with distance from shore than pFe, especially between Stations 2-5 (Figure 9), consistent with a conversion of $\mathrm{dFe}(\mathrm{II})$ to $\mathrm{pFe}$. This confirms earlier hypotheses that $\mathrm{dFe}(\mathrm{II})$ is lost to the particulate phase within the Peruvian ODZ (Vedamati et al., 2014). Prior to the cruise, we anticipated that particulate Fe would be dominated by weakly-adsorbed Fe(II) in the OMZ and by Fe(III) oxyhydroxides at the oxygen gradients (horizontal and vertical), but our synchrotron-based measurements of the speciation of pFe suggest otherwise.

We find that $\mathrm{pFe}$ is overwhelmingly dominated by the Fe(III) redox state below the euphotic zone, even in the ODZ (Figures 2, 5 and 6). This was confirmed by chemical species mapping (Figure 5), and XANES analyses of dozens of individual Fe(III) spots (Figure 7). The detailed EXAFS analyses of two individual Fe(III) spots confirmed that the Fe(III) identified by chemical species mapping and XANES was present as Fe(III) oxyhydroxides in the case of the mid-water column sample (Station 5, $200 \mathrm{~m}$ ), and as a mixture of Fe(III) oxyhydroxides and an $\mathrm{Fe}(\mathrm{III})$-containing clay mineral, consistent with the clay mineral illite, in the case of the nearbottom sample (Station 2, $108 \mathrm{~m}$ ) (Figure 8). As the near-bottom sample was within $15 \mathrm{~m}$ of the bottom, the illite was likely from sediment resuspension.

The identification of the specific Fe(III) species by EXAFS was critical for assessing whether the presence of $\mathrm{pFe}(\mathrm{III})$ resulted from in-situ oxidation in the ODZ, or was simply a result of unavoidable oxidization upon sample recovery. Importantly, both EXAFS required small but significant proportions of the mineral lepidocrocite $(\gamma-\mathrm{Fe}(\mathrm{III}) \mathrm{O}(\mathrm{OH}))$ in the fits. The EXAFS of lepidocrocite shows high amplitude around $\mathrm{k}=6.2 \AA^{-1}$, which was a distinctive feature in both EXAFS sample spectra (Figure 8). Indeed, the ten best linear-combination fits all 
required lepidocrocite. Lepidocrocite is a crystalline Fe oxyhydroxide that is typically formed underwater by oxidation of dissolved $\mathrm{Fe}(\mathrm{II})$ via a green rust (mixed $\mathrm{Fe}(\mathrm{II})-\mathrm{Fe}(\mathrm{III})$ hydroxide) intermediate (Schwertmann and Fechter, 1994). Because lepidocrocite forms by oxidation of aqueous Fe(II) solutions (Cornell and Schwertmann, 2003), and samples used for pFe speciation were collected by in-situ filtration, in which particles are already separated from the aqueous phase at the time of recovery and exposure to air, the presence of lepidocrocite in the ODZ samples is strong evidence that it was formed in-situ in the ODZ, and is not a preservation artifact.

The presence of hydrous ferric oxides (HFO) in the Station 2, $108 \mathrm{~m}$ EXAFS can also be consistent with in-situ production. Even though poorly crystalline HFO and ferrihydrite typically form from the rapid hydrolysis of aqueous Fe(III) solutions (Cornell and Schwertmann, 2003), these mineral forms can also result from the interference of other solutes in the formation of lepidocrocite from aqueous Fe(II) solutions. For example, the presence of silicate, phosphate, and calcium ions has been shown to hinder the formation of lepidocrocite from oxidation of $\mathrm{dFe}(\mathrm{II})$, resulting instead in the formation of poorly crystalline hydrous ferric oxides (HFO) or ferrihydrite (Schwertmann and Thalmann, 1976; Senn et al., 2015; Voegelin et al., 2010; Voegelin et al., 2013). As these solutes are orders of magnitude higher in concentration than Fe in Peruvian ODZ waters, it is reasonable to expect that HFO could have formed from the oxidation of $\mathrm{dFe}(\mathrm{II})$ instead of or in addition to lepidocrocite. HFO was required in the top three linear-combination fits in the Station 2 sample, and in the second and third best two-component linear-combination fits in the Station 5 sample.

Finally, we cannot rule out the possibility that some of the pFe(III) species observed in our samples are a result of oxidation upon sample recovery. Feroxyhyte $(\delta$-Fe(III)O(OH)) was required in the best 2-component fit for the Station 5 sample (Figure 8a), and was required in nine of the top ten 3-component fits for this sample (not shown). While feroxyhyte is found in deep sea iron-manganese nodules where it forms under high pressure conditions (Chukhrov et al., 1977), it can also be formed by extremely rapid oxidation of an Fe(II)-containing hydroxide such as green rust upon exposure to air (Carlson and Schwertmann, 1980; Cornell and Schwertmann, 2003). The feroxyhyte detected in our sample may have therefore formed from the rapid oxidation of green rust upon exposure to air on sample recovery. So while feroxyhyte detected in our samples may not have formed in-situ, its precursor, green rust, is formed by 
direct precipitation of aqueous Fe(II) upon oxidation (Schwertmann and Fechter, 1994) and must have formed in-situ.

Overall, the robust presence of lepidocrocite in our data provides evidence that at least some of the Fe(III) oxyhydroxides in our samples were oxidized in-situ and not simply by exposure of the particulate samples to oxic conditions during sample recovery and handling, especially since samples were protected from oxidation during shipping, storage, and XAS analysis. The other $\mathrm{pFe}$ (III) species observed also support the idea that $\mathrm{dFe}(\mathrm{II})$ is lost by partial (to green rust) or complete (to lepidocrocite or HFO) oxidation in the ODZ, rather than only by adsorption of $\mathrm{dFe}(\mathrm{II})$ to particle surfaces. In contrast to our original expectation, we saw no indication of a rise in $\mathrm{pFe}$ at the outer edges of the $\mathrm{OMZ}$ as the oxygen levels started to increase, and in fact observed the highest pFe concentrations in the upper part of the ODZ (Figure 3 ).

\subsection{Linkages between the Fe and $\mathrm{N}$ cycles in OMZs}

We have argued that oxygen is absent in the ODZ. The other important oxidant in the euphotic zone, hydrogen peroxide (Moffett and Zika, 1987), is also absent below the mixed layer in the Peru upwelling region (Zika et al., 1985). Therefore, nitrate or nitrite is the most likely oxidant. The vertical and horizontal distributions of nitrite and total pFe show a striking similarity within the ODZ of the 2013 GEOTRACES EPZT cruise (Figures 3, 4). Indeed, pFe peaked at the same depth as nitrite at every station. A property-property plot of $\mathrm{pFe}$ and nitrite for samples between $\sigma_{\theta, 0}=26.1-26.55 \mathrm{~kg} / \mathrm{m}^{3}$, the upper part of the ODZ, for Stations 1-11 (Figure 10) show a significant correlation $\left(\mathrm{R}^{2}=0.45 ; \mathrm{p}=0.0002\right)$, with a best-fit slope of 0.60 $\mathrm{nM} \mathrm{pFe} / \mu \mathrm{M}$ nitrite.

The correlation between $\mathrm{pFe}$ and nitrite suggests a role for nitrite as an oxidant for $\mathrm{dFe}(\mathrm{II})$. The abiotic oxidation of $\mathrm{dFe}(\mathrm{II})$ by nitrate $\left(\mathrm{NO}_{3}{ }^{-}\right)$or nitrite $\left(\mathrm{NO}_{2}{ }^{-}\right)$are both thermodynamically favorable, but kinetically inhibited and require a catalyst to proceed at the $\mathrm{pH}$ of seawater. These reactions have been studied in the laboratory since the 1960s: dFe(II) can be oxidized by $\mathrm{NO}_{3}{ }^{-}$to form $\mathrm{Fe}$ oxyhydroxide $(\alpha-\mathrm{FeOOH})$ and $\mathrm{NO}_{2}{ }^{-}, \mathrm{N}_{2} \mathrm{O}, \mathrm{N}_{2}$, or $\mathrm{NH}_{4}{ }^{+}$or by $\mathrm{NO}_{2}{ }^{-}$ to form $\mathrm{N}_{2} \mathrm{O}, \mathrm{N}_{2}$, or $\mathrm{NH}_{4}{ }^{+}$(Buresh and Moraghan, 1976; Picardal, 2012 and references therein; Wullstein and Gilmour, 1966).

Many catalysts for the abiotic oxidation of dFe(II) by nitrite have been identified, including $\mathrm{Cu}^{2+}$ (Moraghan and Buresh, 1977), $\mathrm{Fe}(\mathrm{II})$-binding ligands such as nitrilotriacetic acid 
(NTA) (Kopf et al., 2013), or mineral surfaces such as Fe oxyhydroxides and clays (Coby and Picardal, 2005; Hansen et al., 1994; Sorensen and Thorling, 1991; Tai and Dempsey, 2009; Van Cleemput and Baert, 1983). Some studies of the oxidation of dFe(II) by nitrite have shown a strong autocatalytic effect, where the initial formation of Fe oxyhydroxides greatly accelerates subsequent oxidation kinetics (Buchwald et al., 2016; Jones et al., 2015). Given the dilute nature of the open ocean water column compared to the conditions under which these experiments were generally conducted (subnanomolar compared to millimolar), many of these mechanisms are unlikely to be important in the aqueous phase, but may become significant on particle surfaces.

In the late $1990 \mathrm{~s}$, microbially-mediated $\mathrm{NO}_{3}{ }^{-}$-dependent anaerobic $\mathrm{Fe}$ (II) oxidation (NDFO), an autotrophic metabolism that couples the reduction of nitrate to the oxidation of Fe, was discovered (Straub et al., 1996). Enrichment cultures have demonstrated that this appears to be a widespread metabolism and it has been identified in sediments from freshwater, brackish, and marine sediments (Benz et al., 1998). Recent studies have shown that it can be difficult to experimentally separate chemical oxidation of Fe(II) by microbially produced nitrite from microbial Fe(II) oxidation that is truly coupled to nitrate reduction (Kopf et al., 2013; Picardal, 2012). Indeed, most strains capable of anaerobic Fe(II) oxidation appear to be mixotrophic and require an organic carbon source to fully oxidize Fe(II) (Klueglein et al., 2015).

Recently, genomic data of near-bottom water from the Peruvian ODZ margin showed the presence of nitrate reducing bacteria that are related to a known Fe oxidizer (Scholz et al., 2016). The specific metabolism is not known, but it does point to the possibility of microbiallycatalyzed Fe oxidation in ODZ waters. To our knowledge, the metabolism of putative anaerobic Fe oxidizers in the open ocean ODZ water column has not been investigated. While the details of the coupling of nitrate or nitrite reduction and Fe oxidation in the ODZ water column are unknown, the similar distributions of pFe and nitrite in our section (Figures 4, 10) strongly point to the importance of nitrate and nitrite for oxidizing Fe in the Peruvian ODZ.

Many Fe oxyhydroxide phases, including lepidocrocite, goethite, 2-line ferrihydrite, magnetite, maghemite, and green rust, have been identified as oxidation products of both abiotic (Jones et al., 2015) and biotic (Weber et al., 2006) anaerobic oxidation of Fe(II) conducted in controlled laboratory conditions. Other studies have shown that oxidation of $\mathrm{dFe}(\mathrm{II})$ by $\mathrm{O}_{2}$ also produces a mixture of ferrihydrite, lepidocrocite, and goethite (Jones et al., 2014). Unfortunately, the identities of the mineral phases of the oxidation products alone do not seem to be sufficient to 
constrain whether the mechanism of oxidation was abiotic or microbial, nor do they constrain the nature of the oxidant.

Maxima in pFe and nitrite are also coincident with maxima in $\mathrm{dFe}(\mathrm{II})$ (Figure 4). The coincidence of the secondary nitrite maximum and $\mathrm{dFe}(\mathrm{II})$ has been previously reported in all three of the world's ODZs: Peru (Kondo and Moffett, 2015; Vedamati et al., 2014), Arabian Sea (Kondo and Moffett, 2013; Kondo et al., 2010; Moffett et al., 2007) and Mexican (Heller et al., 2013) ODZs. A similar feature was observed here albeit with less vertical resolution than in the previous studies.

One explanation for the coincidence of nitrite and $\mathrm{dFe}(\mathrm{II})$ is a vertical transport mechanism that couples the oxidation of organic matter by nitrate (nitrate reduction to nitrite) (Bange et al., 2005) with the regeneration of dFe(II) from organic matter (Kondo and Moffett, 2013). Euphotic zone pFe has significant biologically-bound Fe(II) (Figure 2) (von der Heyden et al., 2014), indicating that there is a supply of reduced Fe to the ODZ from above. Regeneration of these particles in the secondary nitrite maximum could result in the accumulation of $\mathrm{dFe}(\mathrm{II})$ and nitrite. The secondary nitrite maximum is significant as a depth horizon characterized by high rates of microbial processes, including denitrification and anaerobic ammonium oxidation (anammox) (Dalsgaard et al., 2012). Accumulation of dFe(II) has been attributed to microbial processes associated with remineralization, dissimilatory reduction, or as part of an Fe acquisition strategy (Kondo and Moffett, 2015). The coincidence of $\mathrm{dFe}(\mathrm{II})$, nitrite and $\mathrm{pFe}(\mathrm{III})$ suggests that this is also a zone of dynamic redox cycling.

It is noteworthy that the oxidation state of $\mathrm{pFe}$ shifts from +2 in the euphotic zone to +3 in the upper ODZ. This suggests that at least some of the change could occur on the particles themselves. Consider a particle formed in the euphotic zone and remineralized in the secondary nitrite maximum. The valence of Fe initially is +2 . Upon colonization by denitrifiers and through organic matter degradation, a fraction of this Fe is released as dFe(II) and diffuses away. However, a significant fraction may be oxidized along with the organic matter by denitrifiers (many of which can oxidize Fe(II) as well as organics) within the particle regime, thus remaining on the particles. However, there are reasons why this is likely to be of secondary importance, at least around the shelf/slope break. First, if the origin of the Fe was sinking particles, we would expect to also see significant Fe oxyhydroxide formation within the oxycline from the oxidation of regenerated Fe(II) by oxygen, yet we do not. Mesoscale eddies, which are widely reported in 
this area (cf., Chelton et al., 2011), could enhance lateral transport of dFe(II) fluxes from sediments. If there is lateral transport of a benthic $\mathrm{dFe}(\mathrm{II})$ source, then this $\mathrm{dFe}(\mathrm{II})$ source must be balanced by a sink, which could be the oxidation to the Fe oxyhydroxides we observed. The oxidation of a benthically derived $\mathrm{dFe}$ (II) is further supported by the light isotopic values of leachable pFe found in the ODZ (Marsay and John, 2014).

A schematic that summarizes the above couplings of the $\mathrm{Fe}$ and $\mathrm{N}$ redox cycles is shown in Figure 11. DFe(II) in the ODZ can thus be supplied by three processes: isopycnal transport of $\mathrm{dFe}(\mathrm{II})$ from sediments, in situ dissimilatory iron reduction (DIR) in microenvironments of particles, or from remineralization of particulate organic matter. The oxidation of $\mathrm{dFe}(\mathrm{II})$ could be in the form of nitrate-dependent Fe(II) oxidation (NDFO), the autotrophic/mixotrophic metabolism that couples the reduction of nitrate to nitrite with the oxidation of $\mathrm{dFe}$ (II) to $\mathrm{pFe}(\mathrm{III})$ (Kappler and Straub, 2005; Straub et al., 1996), or a catalyzed-oxidation of dFe(II) by nitrite (Picardal, 2012) (Figure 11). Microbial catalysis of the oxidation of dFe(II) by nitrite has not been described, but this could also be a possibility.

\subsection{A conceptual model for the redox cycling of Fe in oxygen minimum zones}

The relative rates of supply and loss determine the concentration of $\mathrm{dFe}(\mathrm{II})$ in the ODZ. $\mathrm{DFe}(\mathrm{II})$ is supplied primarily from isopycnal transport from sedimentary DIR, augmented by some $\mathrm{dFe}(\mathrm{II})$ production from remineralization or $\mathrm{Fe}(\mathrm{II})$-containing particulate organic matter by denitrifiers. $\mathrm{DFe}$ (II) is oxidized back to $\mathrm{pFe}$ (III) by nitrate or nitrite with the aid of microbial or abiotic catalysts, respectively. If the abundance of microbial or concentrations of chemical catalysts are not high enough, it is likely that the oxidation of $\mathrm{Fe}(\mathrm{II})$ by nitrite proceeds too slowly to be important. Our data show that there is a higher Fe oxidation rate closer to the margin: the most rapid decrease in $\mathrm{dFe}(\mathrm{II})$ with distance occurs in the stations closest to shore (Figure 9). Indeed, while nitrite explains almost $50 \%$ of the variance of $\mathrm{pFe}$ in our dataset (Figure 10), scatter about the best-fit line indicates that other factors are also important for the formation of $\mathrm{pFe}$, which could include the availability of catalysts. We therefore hypothesize that there is a greater availability of catalysts (mineral or microbial) and thus higher oxidation rate near the margin. The greater availability of catalysts nearshore provides an effective Fe trap that removes most of the $\mathrm{dFe}(\mathrm{II})$. 
If the offshore transport of $\mathrm{dFe}(\mathrm{II})$ is faster than the loss rate of $\mathrm{dFe}(\mathrm{II})$ by oxidation, as would occur if the availability of microbial or mineral surface catalysts decreased, this Fe trap may be leaky and lead to $\mathrm{dFe}(\mathrm{II})$ export into the interior, as we observed to Station 11 . The presence of Ra-228, which has a half-life of $5.74 \mathrm{y}$, in the upper ODZ as far as Station 11 (Sanial et al., accepted), suggests a timescale of transport to Station 11 of months to years. This means that the timescale of oxidation of $\mathrm{dFe}(\mathrm{II})$, especially away from the margin, must be slow enough for $\mathrm{dFe}(\mathrm{II})$ to survive this transport.

\section{Conclusions}

Our direct observations of dissolved and particulate Fe in the Peruvian ODZ water column suggest that an effective redox trap prevents remobilized Fe from the shelf from being transported into the ocean interior, even when neither oxygen nor sulfide is present.

Distributions of Fe species and hydrographic parameters point to nitrite as a key player in the oxidation of $\mathrm{dFe}(\mathrm{II})$ in the absence of oxygen, but this oxidation requires the presence of microbial or abiotic catalysts, such as mineral surfaces from sediment resuspension. Certain environmental conditions may lead to a lack of appropriate catalysts, which may allow leaks in the redox trap so that dissolved Fe can penetrate further into the ocean interior. Future work should be directed to assessing the rates of microbial and abiotic anaerobic Fe oxidation in conditions more appropriate to oceanic ODZs.

\section{Acknowledgements}

This research was supported by NSF grant OCE- 1518110 to P.J.L, OCE-1260273

to J.W.M., OCE-1232986 to B.M.T, and OCE-1233502 to K.W.Bruland, which funded C.P.T. The Advanced Light Source is supported by the Director, Office of Science, Office of Basic Energy Sciences, of the U.S. Department of Energy under Contract No. DE-AC02-05CH11231. Many thanks to Daniel Ohnemus, Sarah Nicholas, and the pump team for collecting and processing the particulate samples; the GEOTRACES sampling team ("supertechs") for collecting the dissolved samples; the crew and chief scientists of the TG Thompson during the GEOTRACES EPZT cruise; the Scripps ODF team for hydrographic measurements and data management; Sarah Nicholas, Colleen Hoffman, Yang Xiang, Kira Mizell, Sirine Fakra, and Josep Roque-Rosell for assistance at beamline 10.3.2 at the Advanced Light Source; Carl 
Lamborg, Greg Cutter, and Virginie Sanial for discussions; four anonymous reviewers for comments that substantially improved the manuscript. 


\section{Tables}

Table 1: Energies used for chemical species mapping and Fe standard pixel densities $\left(\mathrm{cps} / \mu \mathrm{m}^{2}\right)$ for the three beamline visits.

\begin{tabular}{|l|l|l|l|l|l|}
\hline $\begin{array}{l}\text { Beamline visit } \\
\text { (yyyymm) }\end{array}$ & E1 $(\mathrm{eV})$ & E2 $(\mathrm{eV})$ & E3 $(\mathrm{eV})$ & E4 $(\mathrm{eV})$ & $\begin{array}{l}\text { Fe Standard } \\
\left(\mathrm{cps} / \mathrm{\mu m}^{2}\right)\end{array}$ \\
\hline 201404 & 7100 & 7116.5 & 7123 & 7296 & 10980 \\
\hline 201409 & 7100 & 7117.3 & $\begin{array}{l}7123 \text { or } 7129.6 \\
(\mathrm{GT} 2443)\end{array}$ & 7296 & 12363 \\
\hline 201510 & 7100 & 7117.5 & 7124.5 & 7296 & 7769 \\
\hline
\end{tabular}

Table 2: Model Fe sulfide, Fe(II)-containing, and Fe(III) model compounds used in linear combination fits for XANES and EXAFS spectra (indicated by " $x$ "). Abbreviations are those suggested by Whitney and Evans (2010) where possible, or for Source Clays, abbreviations used by the Clays and Clay Minerals society (http://www.clays.org/SOURCE\%20CLAYS/SCdata.html).

\begin{tabular}{|c|c|c|c|c|c|}
\hline Mineral & $\begin{array}{l}\text { Mineralogical } \\
\text { classification }\end{array}$ & $\begin{array}{l}\text { Abbrev. } \\
\#\end{array}$ & Chemical Formula & $\begin{array}{l}\text { XANES } \\
\text { library }\end{array}$ & $\begin{array}{l}\text { EXAFS } \\
\text { library }\end{array}$ \\
\hline \multicolumn{6}{|l|}{ Fe Sulfides } \\
\hline Pyrite & Sulfide & $\mathrm{Py}$ & $\mathrm{Fe}^{2+} \mathrm{S}_{2}$ & $\mathrm{x}$ & $\mathrm{x}$ \\
\hline Pyrrhotite & Sulfide & Po & $\mathrm{Fe}^{2+}{ }_{7} \mathrm{~S}_{8}$ & $\mathrm{x}$ & \\
\hline Mackinawite & Sulfide & Mck & $(\mathrm{Fe}, \mathrm{Ni})_{1+x} \mathrm{~S}$ & $\mathrm{x}$ & \\
\hline Pentlandite & Sulfide & $\mathrm{Pn}$ & $(\mathrm{Fe}, \mathrm{Ni})_{9} \mathrm{~S}_{8}$ & $\mathrm{x}$ & \\
\hline Cubanite & Sulfide & Cbn & $\mathrm{CuFe}_{2} \mathrm{~S}_{3}$ & $\mathrm{x}$ & \\
\hline \multicolumn{6}{|l|}{$\begin{array}{l}\mathrm{Fe}(\mathrm{II}) \\
\text { compounds }\end{array}$} \\
\hline Almandine & Silicate-garnet & Alm & $\mathrm{Fe}^{2+}{ }_{3} \mathrm{Al}_{2} \mathrm{Si}_{3} \mathrm{O}_{12}$ & $\mathrm{x}$ & \\
\hline Augite & $\begin{array}{l}\text { Silicate- } \\
\text { clinopyroxene }\end{array}$ & Aug & $\begin{array}{l}(\mathrm{Ca}, \mathrm{Na})\left(\mathrm{Mg}, \mathrm{Fe}^{2+}, \mathrm{Al}, \mathrm{Fe}^{3+}, \mathrm{Ti}\right)[(\mathrm{Si}, \mathrm{A} \\
\left.1)_{2} \mathrm{O}_{6}\right]\end{array}$ & $\mathrm{x}$ & $\mathrm{x}$ \\
\hline Biotite & $\begin{array}{l}\text { Silicate- } \\
\text { phyllosilicate- } \\
\text { mica }\end{array}$ & $\mathrm{Bt}$ & $\mathrm{KMg}_{2.5} \mathrm{Fe}^{2+}{ }_{0.5} \mathrm{AlSi}_{3} \mathrm{O}_{10}(\mathrm{OH})_{1.75} \mathrm{~F}_{0.25}$ & $\mathrm{x}$ & $\mathrm{x}$ \\
\hline $\begin{array}{l}\text { Chlorite } \\
\text { (Ripidolite) } \\
\text { (CCa2) }\end{array}$ & $\begin{array}{l}\text { Silicate- } \\
\text { phyllosilicate- } \\
\text { chlorite }\end{array}$ & $\mathrm{CCa} 2$ & $(\mathrm{Mg}, \mathrm{Fe}, \mathrm{Al})_{6}(\mathrm{Al}, \mathrm{Si})_{4} \mathrm{O}_{10}(\mathrm{OH})_{8}$ & & $\mathrm{x}$ \\
\hline $\begin{array}{l}\text { Fayalite100 } \\
(\text { Fo40) }\end{array}$ & Silicate-olivine & Fo0 & $\mathrm{Fe}^{2+}{ }_{2} \mathrm{SiO}_{4}$ & $\mathrm{x}$ & \\
\hline $\begin{array}{l}\text { Fayalite60 } \\
\text { (Fo40) }\end{array}$ & Silicate-olivine & Fo40 & 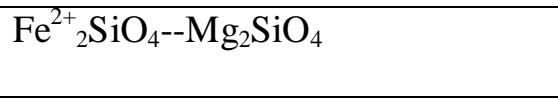 & $\mathrm{x}$ & \\
\hline $\begin{array}{l}\text { Fayalite20 } \\
\text { (Fo40) }\end{array}$ & Silicate-olivine & Fo60 & $\mathrm{Fe}_{2}^{2+} \mathrm{SiO}_{4}--\mathrm{Mg}_{2} \mathrm{SiO}_{4}$ & $\mathrm{x}$ & \\
\hline Ferrosilite & $\begin{array}{l}\text { Silicate- } \\
\text { orthopyroxene }\end{array}$ & Fs & $\mathrm{Fe}^{2+} \mathrm{MgSi}_{2} \mathrm{O}_{6}$ & $\mathrm{x}$ & \\
\hline $\begin{array}{l}\text { Green Rust-Cl, } \\
\text { synthetic }\end{array}$ & $\begin{array}{l}\text { Oxide- } \\
\text { oxyhydroxide }\end{array}$ & $\mathrm{GRCl}$ & $\mathrm{Fe}_{3}^{2+}{ }_{3} \mathrm{Fe}^{3+}(\mathrm{OH})_{8} \mathrm{Cl} . \mathrm{H}_{2} \mathrm{O}$ & $\mathrm{x}$ & \\
\hline
\end{tabular}




\begin{tabular}{|c|c|c|c|c|c|}
\hline $\begin{array}{l}\text { Green Rust- } \\
\text { CO3, synthetic }\end{array}$ & $\begin{array}{l}\text { Oxide- } \\
\text { oxyhydroxide }\end{array}$ & GRCO3 & $\mathrm{Fe}^{2+}{ }_{4} \mathrm{Fe}^{3+}{ }_{2}(\mathrm{OH})_{12} \mathrm{CO}_{3} \cdot 2 \mathrm{H}_{2} \mathrm{O}$ & $\mathrm{x}$ & $\mathrm{x}$ \\
\hline $\begin{array}{l}\text { Green Rust- } \\
\text { SO4, synthetic }\end{array}$ & $\begin{array}{l}\text { Oxide- } \\
\text { oxyhydroxide }\end{array}$ & GRSO4 & $\mathrm{Fe}^{2+}{ }_{4} \mathrm{Fe}^{3+}{ }_{2}(\mathrm{OH})_{12} \mathrm{SO}_{4} \cdot \mathrm{H}_{2} \mathrm{O}$ & $\mathrm{x}$ & $\mathrm{X}$ \\
\hline $\begin{array}{l}\text { Mauna Loa } \\
\text { Glass }\end{array}$ & Silicate-glass & Gla & N/A & $\mathrm{x}$ & \\
\hline Hercynite & Oxide-Spinel & $\mathrm{Hc}$ & $\mathrm{Fe}^{2+} \mathrm{Al}_{2} \mathrm{O}_{4}$ & $\mathrm{x}$ & \\
\hline Hypersthene & $\begin{array}{l}\text { Silicate- } \\
\text { orthopyroxene }\end{array}$ & Hyp & $\mathrm{Mg}^{2+}, \mathrm{Fe}^{2+} \mathrm{SiO}_{3}$ & $\mathrm{X}$ & \\
\hline Ilmenite & Oxide-Ti oxide & Ilm & $\mathrm{Fe}^{2+} \mathrm{TiO}_{3}$ & $\mathrm{x}$ & $V$ \\
\hline Iron sulfate & Sulfate salt & $\mathrm{SO} 4$ & $\mathrm{Fe}^{2+} \mathrm{SO}_{4}$ & & $\mathrm{X}$ \\
\hline Magnetite & Oxide-Spinel & Mag & $\mathrm{Fe}_{2}^{+3} \mathrm{Fe}^{2+} \mathrm{O}_{4}$ & $\mathrm{x}$ & $\mathrm{X}$ \\
\hline Pigeonite & $\begin{array}{l}\text { Silicate- } \\
\text { clinopyroxene }\end{array}$ & Pgt & $\mathrm{Mg}_{1.35} \mathrm{Fe}^{2+}{ }_{0.55} \mathrm{Ca}_{0.1} \mathrm{Si}_{2} \mathrm{O}_{6}$ & $\mathrm{x}$ & \\
\hline Siderite & Carbonate & $\mathrm{Sd}$ & $\mathrm{Fe}^{2+} \mathrm{CO}_{3}$ & $\mathrm{x}$ & \\
\hline Vivianite & Phosphate & Viv & $\mathrm{Fe}_{3}^{+2}\left(\mathrm{PO}_{4}\right)_{2} \cdot 8 \mathrm{H}_{2} \mathrm{O}$ & $\mathrm{x}$ & \\
\hline \multicolumn{6}{|l|}{$\begin{array}{l}\mathrm{Fe}(\mathrm{III}) \\
\text { compounds }\end{array}$} \\
\hline $\begin{array}{l}\text { Aegirine } \\
\text { powder avg }\end{array}$ & $\begin{array}{l}\text { Silicate- } \\
\text { clinopyroxene }\end{array}$ & Aeg & $\mathrm{NaFe}^{3+}\left(\mathrm{Si}_{2} \mathrm{O}_{6}\right)$ & $\mathrm{x}$ & \\
\hline Akaganeite & $\begin{array}{l}\text { Oxide- } \\
\text { oxyhydroxide }\end{array}$ & Aka & $\beta-\mathrm{Fe}^{3+} \mathrm{O}(\mathrm{OH}, \mathrm{Cl})$ & $\mathrm{x}$ & $\mathrm{x}$ \\
\hline Andradite & Silicate-garnet & Adr & $\mathrm{Ca}_{3} \mathrm{Fe}^{3+}{ }_{2} \mathrm{Si}_{3} \mathrm{O}_{12}$ & $\mathrm{x}$ & \\
\hline Biogenic oxide & $\begin{array}{l}\text { Oxide- } \\
\text { oxyhydroxide }\end{array}$ & Box & N/A & $\mathrm{x}$ & $\mathrm{x}$ \\
\hline $\begin{array}{l}\mathrm{Ca} \\
\text { montmorillonit } \\
\mathrm{e}(\mathrm{STx}-1)\end{array}$ & $\begin{array}{l}\text { Silicate- } \\
\text { phyllosilicate- } \\
\text { clay }\end{array}$ & STX & N/A & $\mathrm{x}$ & \\
\hline Fe Alginate & $\begin{array}{l}\text { Organic } \\
\text { complex }\end{array}$ & Alg & $\mathrm{Fe}-\left(\mathrm{C}_{6} \mathrm{H}_{8} \mathrm{O}_{6}\right)_{\mathrm{n}}$ & $\mathrm{x}$ & \\
\hline Fe Dextran & $\begin{array}{l}\text { Organic } \\
\text { complex }\end{array}$ & Dex & $\mathrm{Fe}-\mathrm{H}\left(\mathrm{C}_{6} \mathrm{H}_{10} \mathrm{O}_{5}\right)_{\mathrm{x}} \mathrm{OH}$ & $\mathrm{x}$ & \\
\hline Feroxyhyte & $\begin{array}{l}\text { Oxide- } \\
\text { oxyhydroxide }\end{array}$ & Fxy & $\delta-\mathrm{Fe}^{3+} \mathrm{O}(\mathrm{OH})$ & & \\
\hline $\begin{array}{l}\text { Ferrihydrite (2- } \\
\text { line) }\end{array}$ & $\begin{array}{l}\text { Oxide- } \\
\text { oxyhydroxide }\end{array}$ & Fh2L & $\mathrm{Fe}^{3+}{ }_{5} \mathrm{HO}_{8} \cdot 4 \mathrm{H}_{2} \mathrm{O}$ approx & $\mathrm{x}$ & $\mathrm{x}$ \\
\hline $\begin{array}{l}\text { Ferrihydrite (6- } \\
\text { line) }\end{array}$ & $\begin{array}{l}\text { Oxide- } \\
\text { oxyhydroxide }\end{array}$ & Fh6L & $\mathrm{Fe}^{3+} \mathrm{HO}_{8} \cdot 4 \mathrm{H}_{2} \mathrm{O}$ approx & $\mathrm{x}$ & $\mathrm{x}$ \\
\hline Ferrosmectite & $\begin{array}{l}\text { Aluminosilicat } \\
\text { e clay }\end{array}$ & Sme & N/A & $\mathrm{x}$ & $\mathrm{x}$ \\
\hline Goethite & $\begin{array}{l}\text { Oxide- } \\
\text { hydroxide }\end{array}$ & Gt & $\alpha-\mathrm{Fe}^{3+} \mathrm{O}(\mathrm{OH})$ & $\mathrm{x}$ & $\mathrm{X}$ \\
\hline Hematite & Oxide & $\mathrm{Ht}$ & $\alpha-\mathrm{Fe}^{3+}{ }_{2} \mathrm{O}_{3}$ & $\mathrm{x}$ & \\
\hline $\begin{array}{l}\text { Hydrous Ferric } \\
\text { Oxide-2LFh }\end{array}$ & $\begin{array}{l}\text { Oxide- } \\
\text { oxyhydroxide }\end{array}$ & $\mathrm{HFO}$ & $\mathrm{Fe}^{3+}{ }_{5} \mathrm{HO}_{8} \cdot 4 \mathrm{H}_{2} \mathrm{O}$ approx & $\mathrm{x}$ & $\mathrm{x}$ \\
\hline Hydrous Ferric & Oxide- & Fe4-P4 & $\mathrm{P} / \mathrm{Fe}$ molar ratio of 1.09 & $\mathrm{x}$ & $\mathrm{x}$ \\
\hline
\end{tabular}




\begin{tabular}{|c|c|c|c|c|c|}
\hline Oxide-Fe4-P4 & oxyhydroxide & & & & \\
\hline $\begin{array}{l}\text { Hydrous Ferric } \\
\text { Oxide-Si }\end{array}$ & $\begin{array}{l}\text { Oxide- } \\
\text { oxyhydroxide }\end{array}$ & HFO-Si & $\mathrm{Si} / \mathrm{Fe}$ molar ratio of 0.56 & $\mathrm{x}$ & \\
\hline Illite (IMt1) & $\begin{array}{l}\text { Silicate- } \\
\text { phyllosilicate- } \\
\text { clay }\end{array}$ & IMt1 & N/A & $\mathrm{X}$ & $\mathrm{x}$ \\
\hline $\begin{array}{l}\text { Illite-Smectite } \\
\text { (ISCz-1) }\end{array}$ & $\begin{array}{l}\text { Silicate- } \\
\text { phyllosilicate- } \\
\text { clay }\end{array}$ & $\mathrm{ISCz}$ & N/A & $\mathrm{x}$ & \\
\hline $\begin{array}{l}\text { Kaolinite } \\
\text { (KGa-1b) }\end{array}$ & $\begin{array}{l}\text { Silicate- } \\
\text { phyllosilicate- } \\
\text { clay }\end{array}$ & KGa & N/A & $\mathrm{X}$ & $\nabla$ \\
\hline Lepidocrocite & $\begin{array}{l}\text { Oxide- } \\
\text { oxyhydroxide }\end{array}$ & Lp & $\gamma-\mathrm{Fe}^{3+} \mathrm{O}(\mathrm{OH})$ & $\mathrm{x}$ & $\mathrm{x}$ \\
\hline Maghemite & Oxide-Spinel & Mgh & $\gamma-\mathrm{Fe}^{3+}{ }_{2} \mathrm{O}_{3}$ & $\mathrm{x}$ & \\
\hline $\begin{array}{l}\text { Montmorillonit } \\
\text { e (SCa-3) }\end{array}$ & $\begin{array}{l}\text { Silicate- } \\
\text { phyllosilicate- } \\
\text { clay }\end{array}$ & $\mathrm{SCa}$ & N/A & $\mathrm{x}$ & \\
\hline $\begin{array}{l}\text { Nontronite } \\
\text { (Nau-1) }\end{array}$ & $\begin{array}{l}\text { Silicate- } \\
\text { phyllosilicate- } \\
\text { clay }\end{array}$ & Nau1 & N/A & $\mathrm{x}$ & $\mathrm{x}$ \\
\hline $\begin{array}{l}\text { Nontronite } \\
\text { (Nau-2) }\end{array}$ & $\begin{array}{l}\text { Silicate- } \\
\text { phyllosilicate- } \\
\text { clay }\end{array}$ & Nau2 & $\mathrm{N} / \mathrm{t}$ & $\mathrm{x}$ & \\
\hline $\begin{array}{l}\mathrm{Na} \\
\text { montmorillonit } \\
\text { e (SWy-2) }\end{array}$ & $\begin{array}{l}\text { Silicate- } \\
\text { phyllosilicate- } \\
\text { clay }\end{array}$ & SWy & N/A & $\mathrm{x}$ & $\mathrm{x}$ \\
\hline SPG2_outer & $\begin{array}{l}\text { Ferromanganes } \\
\text { e nodule }\end{array}$ & SPG2ou & N/A & & $\mathrm{x}$ \\
\hline SPG2_inner & $\begin{array}{l}\text { Ferromanganes } \\
\text { e nodule }\end{array}$ & SPG2in & N/A & & $\mathrm{x}$ \\
\hline
\end{tabular}


Table 3: Samples analyzed at the synchrotron, indicating when they were run and whether chemical species data were corrected (see section 3.5). The size of the scale bar in Figure 5 maps is indicated here.

\begin{tabular}{|c|c|c|c|c|c|}
\hline Stn & Depth & GT Number & $\begin{array}{c}\text { Beamline visit } \\
\text { (уyyymm) }\end{array}$ & Corrected & Scale bar $[\mu \mathrm{m}]$ \\
\hline 2 & 15 & 2280 & 201404 & & 400 \\
\hline 2 & 38 & 2279 & 201404 & & 100 \\
\hline 2 & 55 & 2278 & 201404 & & 400 \\
\hline 2 & 70 & 2277 & 201404 & & 100 \\
\hline 2 & 108 & 2276 & 201404 & & 400 \\
\hline 2 & 108 & 2276 (repeat) & 201404 & & 70 \\
\hline 3 & 35 & 2329 & 201404 & & 400 \\
\hline 3 & 65 & 2328 & 201404 & 2 & 100 \\
\hline 3 & 90 & 2327 & 201404 & 5 & 100 \\
\hline 3 & 170 & 2326 & 201409 & E & 400 \\
\hline 3 & 170 & 2326 (repeat) & 201409 & - & 100 \\
\hline 5 & 15 & 2446 & 201510 & $\mathrm{x}$ & 400 \\
\hline 5 & 75 & 2445 & 201510 & $\mathrm{x}$ & 299 \\
\hline 5 & 120 & 2444 & 201510 & $\mathrm{x}$ & 400 \\
\hline 5 & 200 & 2443 & 201409 & & 100 \\
\hline 5 & 200 & 2443 (repeat) & 201510 & $\mathrm{x}$ & 299 \\
\hline 5 & 600 & 2442 & 201510 & $\mathrm{x}$ & 400 \\
\hline
\end{tabular}


Table 4: Error estimates for Fe species (see section 3.5).

\begin{tabular}{|c|c|c|c|c|c|c|}
\hline & $\begin{array}{l}\text { Description of } \\
\text { error }\end{array}$ & $\begin{array}{c}\text { How } \\
\text { determined }\end{array}$ & $\begin{array}{c}\mathrm{RSD}_{\mathrm{Fe}(\mathrm{II})} \\
(\%)\end{array}$ & $\begin{array}{c}\mathrm{RSD}_{\mathrm{Fe}(\mathrm{III})} \\
(\%)\end{array}$ & $\begin{array}{c}\mathrm{RSD}_{\mathrm{Fe}-} \\
\text { sulfide } \\
(\%)\end{array}$ & $\begin{array}{l}\mathrm{RSD}_{\mathrm{FeTotal}} \\
(\%)\end{array}$ \\
\hline$R S D_{\text {dist }}$ & $\begin{array}{l}\text { Variability in } \\
\text { distribution of } \\
\text { Fe on filter }\end{array}$ & $\begin{array}{c}\text { GT2276 rerun } \\
\text { during } \\
201404\end{array}$ & 9 & 3 & 0.1 & \\
\hline$R S D_{2014 \text { beam }}$ & $\begin{array}{c}\text { Variability } \\
\text { between } \\
\text { beamline visits } \\
\text { in } 2014\end{array}$ & $\begin{array}{l}\text { GT2326 run } \\
\text { 201404, } \\
201409\end{array}$ & 16 & 7 & & 11 \\
\hline$R S D_{2014-15 b e a m}$ & $\begin{array}{l}\text { Variability } \\
\text { between } \\
\text { beamline visits } \\
\text { in } 2014-15\end{array}$ & $\begin{array}{l}\text { GT2443 run } \\
201404, \\
201409\end{array}$ & 53 & 38 & 63 & 30 \\
\hline$R S D_{2015 \text { corr } 1}$ & $\begin{array}{c}\text { Variability } \\
\text { between } \\
\text { beamline visits } \\
\text { in } 2014-15, \text { after } \\
\text { correction } 1\end{array}$ & $\begin{array}{c}\text { GT2443 run } \\
201409, \\
201510\end{array}$ & 16 & 9 & 27 & 19 \\
\hline
\end{tabular}




\section{Figure Captions}

Figure 1: (A) Cruise track of the Eastern Pacific Zonal Transect (EPZT-GP16) cruise. All full stations indicated in black dots; "demi" stations in grey dots. Thick black box denotes eastern portion (stations 1-11) of the cruise discussed in this paper. Hydrographic parameters $\left(\mathrm{O}_{2}, \mathrm{NO}_{3}\right.$, $\left.\mathrm{NO}_{2}{ }^{-}\right)$and total dissolved Fe measured at all stations $(\mathrm{n}=11)$; dissolved $\mathrm{Fe}(\mathrm{II})$ and total particulate Fe measured at full stations $(n=8)$. (B) Greater bathymetric detail for Stations 1-5, outlined in thin black box in (A), showing stations (white crosses) where synchrotron analyses of $\mathrm{pFe}$ were done $(\mathrm{n}=3)$. Note that station numbers increase offshore, except for station 1 , which is out of sequence and is offshore of Station 5. Background shading and scale bar show bathymetry.

Figure 2: Fractional concentrations of pFe species for three margin stations. A) Fraction Fe(III), B) Fraction Fe(II), C) Fraction Fe sulfide for Stations 2 (squares), 3 (triangles) and 5 (circles). All data collected in 2014 are filled black symbols. Raw data collected in 2015 are small open symbols, and corrected data (see section 3.5) are filled grey symbols. Error bars are standard deviations calculated from $R S D_{\text {beam }}$ for Stations 2,3, $R S D_{2014-15 b e a m}$ for Station 5 raw, and from $R S D_{2015 \text { corr } 1}$ for Station 5 corrected (Tables 3, 4).

Figure 3: Upper $500 \mathrm{~m}$ sections of OMZ study area indicated in Figure 1. Sections show concentrations of $\mathrm{A})$ oxygen $(5 \mu \mathrm{M}$ black contours up to $25 \mu \mathrm{M}), \mathrm{B})$ nitrite $(1 \mu \mathrm{M}$ black contours to $5 \mu \mathrm{M}), \mathrm{C})$ nitrate (5 $\mu \mathrm{M}$ black contours), D) dissolved Fe(II) (0.25 nM black contours to 1.5 $\mathrm{nM}), \mathrm{E})$ total particulate $\mathrm{Fe}(0.25 \mathrm{nM}$ black contours to $1.5 \mathrm{nM})$, and F) dissolved $\mathrm{Fe}(0.25 \mathrm{nM}$ black contours to $1.5 \mathrm{nM})$. Potential density $\left(\sigma_{\theta, 0}\right)$ overlaid on each panel $\left(0.5 \mathrm{~kg} / \mathrm{m}^{3}\right.$ white contours). Station numbers where data available indicated in red above each section plot.

Figure 4: Profiles of total pFe by ICP-MS (black circles), dFe(II) (red squares), nitrite (blue triangles) and oxygen (green line) for the upper $500 \mathrm{~m}$. Margin stations on top row, and open ocean stations on bottom row, arranged from east on right to west on left. Horizontal dashed line in Station 2 and 3 panels indicates water depth.

Figure 5: Tricolor synchrotron chemical maps showing the distribution of pFe species; blue color shows Fe(III), green shows Fe(II) and red shows Fe Sulfide species. The white levels are set to the same values for the blue, green, and red channels, and are adjusted to the pixel density of the 
Fe standard (Table 1) to account for different detector configurations between beamline visits. The intensities of the colors in the blue, green, and red channels indicate the concentrations of $\mathrm{Fe}(\mathrm{III}), \mathrm{Fe}(\mathrm{II})$, and Fe sulfide species in each pixel. All maps are approximately $1000 \mu \mathrm{m}$ across. White scale bars are automatically generated by the plotting program and are $70 \mu \mathrm{m}, 100 \mu \mathrm{m}$, $299 \mu \mathrm{m}$ or $400 \mu \mathrm{m}$ (exact lengths indicated in Table 2). Depths of the ODZ pFe maxima are indicated by *. The predominant blue color of the chemical species maps at the pFe maxima indicate that $\mathrm{pFe}$ is present as mostly $\mathrm{Fe}(\mathrm{III})$.

Figure 6: Absolute concentrations of total pFe determined by XRF (black circles) or ICP-MS (white circles), and pFe species from chemical species mapping: $\mathrm{Fe}(\mathrm{III})$ (blue triangles), $\mathrm{Fe}$ (II) (green squares), Fe-sulfide (red diamonds) for Stations 5, 3, and 2. Error bars for XRF Fe and Fe species are one standard deviation, calculated from $R S D_{\text {beam }}$ (Table 4) for Stations 2, 3 collected in 2014, and from $R S D_{\text {corr }}$ (Table 4) for Station 5 collected mostly in 2015. Error bars for ICPMS Fe are propagated from uncertainty in the blanks and repeat analyses. Horizontal dashed line in Station 2 and 3 panels indicates water depth.

Figure 7: Fe K-edge $\mu$-XANES spectra of multiple spots from samples from the depth of the ODZ pFe max (grey), overlain by model Fe species (colors). Locations of $\mu$-XANES indicated as orange circles in chemical species maps in inset. Black, solid lines are 18 spectra collected in 2014 (Stn 2-70 m, n = 9, top map and Stn3-90 m, n = 9, middle map); light grey, dashed lines are 15 spectra collected in 2015 (Station 5-120 m, bottom map); red, green, and dark blue lines are the Fe sulfide (pyrite), $\mathrm{Fe}(\mathrm{II})\left(\mathrm{FeSO}_{4}\right)$, and $\mathrm{Fe}(\mathrm{III})$ (HFO) model Fe species used in the chemical mapping calculation; light blue line is a $25 \% / 75 \%$ mixture of the $\mathrm{Fe}(\mathrm{II})$ and $\mathrm{Fe}(\mathrm{III})$ model species, respectively, which is a good approximation of most of the XANES spectra from the pFe maximum, and consistent with the quantification of Fe redox state by chemical mapping (Figure 5).

Figure 8: Fe K-edge $\mu$-EXAFS spectroscopy of an iron-rich Fe(III) spot from Station 5, $200 \mathrm{~m}$ (A), and from Station 2, $108 \mathrm{~m}(\mathrm{~B})$, both within the oxygen deficient zone. The best fit (green line) to the sample spectra (open squares) is indicated. EXAFS spectra of model Fe species appearing in the fit also indicated (solid lines above the sample spectra and fits) (See Table 2 for description of model species). 
Figure 9: Average concentrations of $\mathrm{pFe}$ (closed circles) and $\mathrm{dFe}(\mathrm{II})$ (open circles) as a function of distance from shore, plotted on a $\log _{10}$ scale. Average concentrations are depth weighted for samples in the upper ODZ (defined here as $\sigma_{\theta, 0}$ between the $26.1-26.55 \mathrm{~kg} / \mathrm{m}^{3}$ ). Station numbers indicated at top of figure.

Figure 10: Relationship between nitrite and particulate iron $(\mathrm{pFe})$ for samples in the upper part of the ODZ between $\sigma_{\theta, 0}=26.1-26.55 \mathrm{~kg} / \mathrm{m}^{3}$, approximately $100-300 \mathrm{~m}$, for Stations $1-11$. The red line is the ordinary least squares regression fit: $\mathrm{R}^{2}=0.45 ; \mathrm{p}=0.0002$. Colorbar indicates station number, with more margin-influenced stations in blue and more open ocean stations in red.

Figure 11: Schematic illustrating the coupling of Fe and N redox cycling in the ODZ water column. Oxidation reactions are blue arrows; reduction reactions are green arrows. Redox reactions are mediated by microbial catalysts (triangles for autotroph/mixotroph; ovals for heterotrophs) or abiotic or unknown microbial catalysts (rectangle). Non redox processes that are sources or sinks of $\mathrm{dFe}(\mathrm{II})$ and $\mathrm{pFe}(\mathrm{III})$ are black dashed arrows. Thinner arrows represent more speculative reactions. Abbreviations are: $\mathrm{NDFO}-\mathrm{NO}_{3}{ }^{-}$-dependent $\mathrm{Fe}(\mathrm{II})$ oxidation; denitdenitrification; remin — remineralization; FO - Fe(II) oxidation; DIR — dissimilatory iron reduction; POC_-particulate organic carbon. See section 5.3 for discussion. 


\section{Supplementary Figure Captions}

Figure S1: Particulate Fe:P (mmol:mol). Vertical dashed line is a typical plankton stoichiometric Fe:P ratio (5 mmol/mol) from field studies (Twining and Baines 2013). Horizontal solid line is the water depth, where less than $500 \mathrm{~m}$.

Figure S2: Particulate Fe:Al (mol:mol). Vertical dashed line is the upper continental crust (UCC) average $(0.21 \mathrm{~mol} / \mathrm{mol})$ (Taylor and McLennan 1995). Horizontal solid line is the water depth, where less than $500 \mathrm{~m}$. 


\section{References}

Bange, H.W., Naqvi, S.W.A., Codispoti, L.A., 2005. The nitrogen cycle in the Arabian Sea. Progress in Oceanography 65, 145-158.

Benz, M., Brune, A., Schink, B., 1998. Anaerobic and aerobic oxidation of ferrous iron at neutral $\mathrm{pH}$ by chemoheterotrophic nitrate-reducing bacteria. Archives of Microbiology 169, 159165.

Biller, D.V., Bruland, K.W., 2012. Analysis of Mn, Fe, Co, Ni, Cu, Zn, Cd, and Pb in seawater using the Nobias-chelate PA1 resin and magnetic sector inductively coupled plasma mass spectrometry (ICP-MS). Marine Chemistry 130-131, 12-20.

Bishop, J.K.B., Lam, P.J., Wood, T.J., 2012. Getting good particles: accurate sampling of particles by large volume in-situ filtration. Limnology and Oceanography Methods 10, 681-710.

Bopp, L., Le Quere, C., Heimann, M., Manning, A.C., Monfray, P., 2002. Climate-induced oceanic oxygen fluxes: Implications for the contemporary carbon budget. Global Biogeochemical Cycles 16.

Boyd, P.W., Jickells, T., Law, C.S., Blain, S., Boyle, E.A., Buesseler, K.O., Coale, K.H., Cullen, J.J., de Baar, H.J.W., Follows, M., Harvey, M., Lancelot, C., Levasseur, M., Owens, N.P.J., Pollard, R., Rivkin, R.B., Sarmiento, J., Schoemann, V., Smetacek, V., Takeda, S., Tsuda, A., Turner, S., Watson, A.J., 2007. Mesoscale iron enrichment experiments 1993-2005: Synthesis and future directions. Science 315, 612-617.

Bruchert, V., Jorgensen, B.B., Neumann, K., Riechmann, D., Schlosser, M., Schulz, H., 2003. Regulation of bacterial sulfate reduction and hydrogen sulfide fluxes in the central Namibian coastal upwelling zone. Geochimica Et Cosmochimica Acta 67, 4505-4518.

Bruland, K.W., Rue, E.L., Smith, G.J., DiTullio, G.R., 2005. Iron, macronutrients and diatom blooms in the Peru upwelling regime: brown and blue waters of Peru. Marine Chemistry 93, 81-103.

Buchwald, C., Grabb, K., Hansel, C.M., Wankel, S.D., 2016. Constraining the role of iron in environmental nitrogen transformations: Dual stable isotope systematics of abiotic NO2reduction by $\mathrm{Fe}(\mathrm{II})$ and its production of N2O. Geochimica Et Cosmochimica Acta 186, $1-12$.

Buresh, R.J., Moraghan, J.T., 1976. Chemical Reduction of Nitrate by Ferrous Iron. Journal of Environmental Quality 5, 320-325.

Canfield, D.E., Stewart, F.J., Thamdrup, B., De Brabandere, L., Dalsgaard, T., Delong, E.F., Revsbech, N.P., Ulloa, O., 2010. A Cryptic Sulfur Cycle in Oxygen-Minimum-Zone Waters off the Chilean Coast. Science 330, 1375-1378. 
Carlson, L., Schwertmann, U., 1980. Natural occurrence of feroxyhite (d-FeOOH). Clays Clay Miner 28, 272-280.

Chelton, D.B., Schlax, M.G., Samelson, R.M., 2011. Global observations of nonlinear mesoscale eddies. Progress in Oceanography 91, 167-216.

Chever, F., Rouxel, O.J., Croot, P.L., Ponzevera, E., Wuttig, K., Auro, M., 2015. Total dissolvable and dissolved iron isotopes in the water column of the Peru upwelling regime. Geochimica et Cosmochimica Acta 162, 66-82.

Chukhrov, F.V., Zvyagin, B.B., Gorshkov, A.I., Yermilova, L.P., Korovushkin, V.V., Rudnitskaya, Y.S., Yakubovskaya, N.Y., 1977. Feroxyhyte, a new modification of FeOOH. International Geology Review 19, 873-890.

Coby, A.J., Picardal, F.W., 2005. Inhibition of NO3- and NO2- reduction by microbial Fe(III) reduction: Evidence of a reaction between NO2- and cell surface-bound Fe2+. Applied and Environmental Microbiology 71, 5267-5274.

Cornell, R.M., Schwertmann, U., 2003. The iron oxides: structure, properties, reactions, occurrences and uses. John Wiley \& Sons.

Croot, P.L., Laan, P., 2002. Continuous shipboard determination of Fe(II) in polar waters using flow injection analysis with chemiluminescence detection. Analytica Chimica Acta 466, 261-273.

Cutter, G.A., Andersson, P., Codispoti, L., Croot, P., Francois, F., Lohan, M.C., Obata, H., Rutgers van der Loeff, M., 2014. Sampling and Sample-handling Protocols for GEOTRACES Cruises, v2.0. http://geotraces.org/images/stories/documents/intercalibration/Cookbook.pdf.

Cutter, G.A., Bruland, K.W., 2012. Rapid and noncontaminating sampling system for trace elements in global ocean surveys. Limnology and Oceanography: Methods 10, 425-436.

Cutter, G.A., Nielsdottir, M.C., 2014. Characterizing redox conditions in oxygen-deficient waters off Peru during the 2013 US GEOTRACES Zonal Transect, Abstract OS22B-06, 2014 Fall Meeting, AGU. AGU, San Francisco, CA, pp. OS22B-06.

Dalsgaard, T., Thamdrup, B., Farías, L., Revsbech, N.P., 2012. Anammox and denitrification in the oxygen minimum zone of the eastern South Pacific. Limnology and Oceanography 57, 1331-1346.

Dugdale, R.C., Goering, J.J., Barber, R.T., Smith, R.L., Packard, T.T., 1977. Denitrification and hyydrogen-sulfide in Peru upwelling region during 1976. Deep-Sea Research 24, 601608.

Hansen, H.C.B., Borggaard, O.K., Sorensen, J., 1994. Evaluation of the free energy of formation of $\mathrm{Fe}(\mathrm{II})-\mathrm{Fe}(\mathrm{III})$ hydroxide-sulphate (green rust) and its reduction of nitrite. Geochimica Et Cosmochimica Acta 58, 2599-2608. 
Heller, M.I., Moffett, J.W., Tiano, L., Revsbech, N.P., 2013. Distribution of Fe(II), H2O2 and O2 in the Mexican OMZ: Potential biogeochemical processes causing their occurrence. Abstracts of Papers of the American Chemical Society 245.

Hong, H.S., Kester, D.R., 1986. Redox state of iron in offshore waters of Peru Limnology and Oceanography 31, 512-524.

Hopkinson, B.M., Barbeau, K.A., 2007. Organic and redox speciation of iron in the eastern tropical North Pacific suboxic zone. Marine Chemistry 106, 2-17.

Johnson, K.S., Coale, K.H., Elrod, V.A., Neil W, T., 1994. Iron photochemistry in seawater from the equatorial Pacific. Marine Chemistry 46, 319-334.

Jones, A.M., Griffin, P.J., Collins, R.N., Waite, T.D., 2014. Ferrous iron oxidation under acidic conditions - The effect of ferric oxide surfaces. Geochimica Et Cosmochimica Acta 145, $1-12$.

Jones, L.C., Peters, B., Lezama Pacheco, J.S., Casciotti, K.L., Fendorf, S., 2015. Stable Isotopes and Iron Oxide Mineral Products as Markers of Chemodenitrification. Environmental Science \& Technology 49, 3444-3452.

Kappler, A., Straub, K.L., 2005. Geomicrobiological cycling of iron. Reviews in Mineralogy and Geochemistry 59, 85-108.

Kessler, W.S., 2006. The circulation of the eastern tropical Pacific: A review. Progress in Oceanography 69, 181-217.

King, D.W., Lounsbury, H.A., Millero, F.J., 1995. Rates and Mechanism of Fe(1l) Oxidation at Nanomolar Total Iron Concentrations Environmental Science \& Technology 29, 818824.

Klueglein, N., Picardal, F., Zedda, M., Zwiener, C., Kappler, A., 2015. Oxidation of Fe(II)EDTA by nitrite and by two nitrate-reducing Fe(II)-oxidizing Acidovorax strains. Geobiology 13, 198-207.

Kondo, Y., Moffett, J.W., 2013. Dissolved Fe(II) in the Arabian Sea oxygen minimum zone and western tropical Indian Ocean during the inter-monsoon period. Deep Sea Research Part I: Oceanographic Research Papers 73, 73-83.

Kondo, Y., Moffett, J.W., 2015. Iron redox cycling and subsurface offshore transport in the eastern tropical South Pacific oxygen minimum zone. Marine Chemistry 168, 95-103.

Kondo, Y., Moffett, J.W., Obata, H., Nishioka, J., 2010. Fe(II) distribution in the Arabian Sea oxygen minimum zone and Western tropical Indian Ocean from GEOTRACES KH-09-5. Geochimica et Cosmochimica Acta 74, A528-A528. 
Kopf, S.H., Henny, C., Newman, D.K., 2013. Ligand-Enhanced Abiotic Iron Oxidation and the Effects of Chemical versus Biological Iron Cycling in Anoxic Environments. Environmental Science \& Technology 47, 2602-2611.

Lam, P.J., Ohnemus, D.C., Marcus, M.A., 2012. The speciation of marine particulate iron adjacent to active and passive continental margins. Geochimica Et Cosmochimica Acta $80,108-124$.

Landing, W.M., Bruland, K.W., 1987. The Contrasting Biogeochemistry of Iron and Manganese in the Pacific-Ocean. Geochimica Et Cosmochimica Acta 51, 29-43.

Lyons, T.W., Severmann, S., 2006. A critical look at iron paleoredox proxies: New insights from modern euxinic marine basins. Geochimica Et Cosmochimica Acta 70, 5698-5722.

Marcus, M.A., 2010. X-ray photon-in/photon-out methods for chemical imaging. Trends in Analytical Chemistry 29, 508-517.

Marcus, M.A., MacDowell, A.A., Celestre, R., Manceau, A., Miller, T., Padmore, H.A., Sublett, R.E., 2004. Beamline 10.3.2 at ALS: a hard X-ray microprobe for environmental and materials sciences. Journal of Synchrotron Radiation 11, 239-247.

Marsay, C.M., John, S.G., 2014. Distribution and Isotopic Signature of "Ligand-leachable" Particulate Iron in the Eastern Tropical South Pacific: Initial Results from US GEOTRACES EPZT, Abstract OS23E-1268, 2014 Fall Meeting, AGU. AGU, San Francisco, CA.

Millero, F.J., Sotolongo, S., 1989. The Oxidation of Fe(II) with H2O2 in Seawater. Geochimica Et Cosmochimica Acta 53, 1867-1873.

Millero, F.J., Sotolongo, S., Izaguirre, M., 1987. The Oxidation-Kinetics of Fe(II) in Seawater. Geochimica Et Cosmochimica Acta 51, 793-801.

Moffett, J.W., Goepfert, T.J., Naqvi, S.W.A., 2007. Reduced iron associated with secondary nitrite maxima in the Arabian Sea. Deep Sea Research Part I: Oceanographic Research Papers 54, 1341-1349.

Moffett, J.W., Zika, R.G., 1987. Reaction kinetics of hydrogen peroxide with copper and iron in seawater. Environmental Science \& Technology 21, 804-810.

Moraghan, J.T., Buresh, R.J., 1977. Chemical reduction of nitrite and nitrous oxide by ferrous iron. Soil Science Society of America Journal 41, 47-50.

Noffke, A., Hensen, C., Sommer, S., Scholz, F., Bohlen, L., Mosch, T., Graco, M., Wallmann, K., 2012. Benthic iron and phosphorus fluxes across the Peruvian oxygen minimum zone. Limnology and Oceanography 57, 851-867.

Ohnemus, D.C., Auro, M.E., Sherrell, R.M., Lagerstrom, M., Morton, P.L., Twining, B.S., Rauschenberg, S., Lam, P.J., 2014. Laboratory intercomparison of marine particulate 
digestions including Piranha: a novel chemical method for dissolution of polyethersulfone filters. Limnology and Oceanography-Methods 12, 530-547.

Ohnemus, D.C., Lam, P.J., 2015. Cycling of lithogenic marine particles in the US GEOTRACES North Atlantic transect. Deep Sea Research Part II: Topical Studies in Oceanography 116, 283-302.

Ohnemus, D.C., Rauschenberg, S., Cutter, G.A., Fitzsimmons, J.N., Sherrell, R.M., Twining, B.S., 2016. Elevated trace metal content of prokaryotic communities associated with marine oxygen deficient zones. Limnology and Oceanography.

Parker, C.E., Brown, M.T., Bruland, K.W., 2016. Scandium in the open ocean: A comparison with other group 3 trivalent metals. Geophysical Research Letters 43, 2758-2764.

Picardal, F., 2012. Abiotic and microbial interactions during anaerobic transformations of Fe(II) and NOX. Frontiers in Microbiology 3.

Raiswell, R., Canfield, D.E., 2012. The Iron Biogeochemical Cycle past and present. Geochemical Perspectives 1, 1-220.

Revsbech, N.P., Larsen, L.H., Gundersen, J., Dalsgaard, T., Ulloa, O., Thamdrup, B., 2009. Determination of ultra-low oxygen concentrations in oxygen minimum zones by the STOX sensor. Limnology and Oceanography-Methods 7, 371-381.

Rose, A.L., Waite, T.D., 2001. Chemiluminescence of Luminol in the Presence of Iron(II) and Oxygen: Oxidation Mechanism and Implications for Its Analytical Use. Analytical Chemistry 73, 5909-5920.

Roy, E.G., Wells, M.L., King, D.W., 2008. Persistence of iron(II) in surface waters of the western subarctic Pacific. Limnology and Oceanography 53, 89-98.

Rue, E.L., Smith, G.J., Cutter, G.A., Bruland, K.W., 1997. The response of trace element redox couples to suboxic conditions in the water column. Deep-Sea Research Part IOceanographic Research Papers 44, 113-134.

Sanial, V., Kipp, L.E., Henderson, P., van Beek, P., Reyss, J.L., Hammond, D.E., Hawco, N.J., Saito, M.A., Resing, J.A., Sedwick, P., Moore, W.S., Charette, M.A., accepted. Radium228 as a tracer of dissolved trace element inputs from the Peruvian continental margin. Marine Chemistry.

Scholz, F., Löscher, C.R., Fiskal, A., Sommer, S., Hensen, C., Lomnitz, U., Wuttig, K., Göttlicher, J., Kossel, E., Steininger, R., Canfield, D.E., 2016. Nitrate-dependent iron oxidation limits iron transport in anoxic ocean regions. Earth and Planetary Science Letters 454, 272-281.

Scholz, F., McManus, J., Mix, A.C., Hensen, C., Schneider, R.R., 2014a. The impact of ocean deoxygenation on iron release from continental margin sediments. Nature Geoscience 7, 433-437. 
Scholz, F., Severmann, S., McManus, J., Hensen, C., 2014b. Beyond the Black Sea paradigm: The sedimentary fingerprint of an open-marine iron shuttle. Geochim. Cosmochim. Acta 127, 368-380.

Schwertmann, U., Fechter, H., 1994. The formation of green rust and its transformation to Lepidocrocite. Clay Minerals 29, 87-92.

Schwertmann, U., Thalmann, H., 1976. The influence of [Fe (II)],[Si], and pH on the formation of lepidocrocite and ferrihydrite during oxidation of aqueous FeC12 solutions. Clay Minerals 11, 189-200.

Senn, A.-C., Kaegi, R., Hug, S.J., Hering, J.G., Mangold, S., Voegelin, A., 2015. Composition and structure of $\mathrm{Fe}(\mathrm{III})$-precipitates formed by $\mathrm{Fe}(\mathrm{II})$ oxidation in water at near-neutral $\mathrm{pH}$ : Interdependent effects of phosphate, silicate and Ca. Geochimica Et Cosmochimica Acta 162, 220-246.

Sorensen, J., Thorling, L., 1991. Stimulation by lepidocrocite ( $\gamma$ - FeOOH) of Fe(II)-dependent nitrite reduction. Geochimica Et Cosmochimica Acta 55, 1289-1294.

Stramma, L., Johnson, G.C., Sprintall, J., Mohrholz, V., 2008. Expanding Oxygen-Minimum Zones in the Tropical Oceans. Science 320, 655-658.

Straub, K.L., Benz, M., Schink, B., Widdel, F., 1996. Anaerobic, nitrate-dependent microbial oxidation of ferrous iron. Applied and Environmental Microbiology 62, 1458-1460.

Tai, Y.-L., Dempsey, B.A., 2009. Nitrite reduction with hydrous ferric oxide and Fe(II): Stoichiometry, rate, and mechanism. Water Research 43, 546-552.

Tiano, L., Garcia-Robledo, E., Dalsgaard, T., Devol, A.H., Ward, B.B., Ulloa, O., Canfield, D.E., Peter Revsbech, N., 2014. Oxygen distribution and aerobic respiration in the north and south eastern tropical Pacific oxygen minimum zones. Deep Sea Research Part I: Oceanographic Research Papers 94, 173-183.

Toner, B.M., German, C.R., Dick, G.J., Breier, J.A., 2016. Deciphering the Complex Chemistry of Deep-Ocean Particles Using Complementary Synchrotron X-ray Microscope and Microprobe Instruments. Accounts of Chemical Research 49, 128-137.

Ulloa, O., Canfield, D.E., DeLong, E.F., Letelier, R.M., Stewart, F.J., 2012. Microbial oceanography of anoxic oxygen minimum zones. Proceedings of the National Academy of Sciences 109, 15996-16003.

Van Cleemput, O., Baert, L., 1983. Nitrite stability influenced by iron compounds. Soil Biology \& Biochemistry 15, 137-140.

Vedamati, J., Goepfert, T., Moffett, J.W., 2014. Iron speciation in the eastern tropical South Pacific oxygen minimum zone off Peru. Limnol. Oceanogr 95, 1945-1957. 
Voegelin, A., Kaegi, R., Frommer, J., Vantelon, D., Hug, S.J., 2010. Effect of phosphate, silicate, and $\mathrm{Ca}$ on $\mathrm{Fe}(\mathrm{III})$-precipitates formed in aerated $\mathrm{Fe}(\mathrm{II})$ - and $\mathrm{As}(\mathrm{III})$-containing water studied by X-ray absorption spectroscopy. Geochimica Et Cosmochimica Acta 74, 164-186.

Voegelin, A., Senn, A.-C., Kaegi, R., Hug, S.J., Mangold, S., 2013. Dynamic Fe-precipitate formation induced by $\mathrm{Fe}(\mathrm{II})$ oxidation in aerated phosphate-containing water.

Geochimica Et Cosmochimica Acta 117, 216-231.

von der Heyden, B.P., Hauser, E.J., Mishra, B., Martinez, G.A., Bowie, A.R., Tyliszczak, T., Mtshali, T.N., Roychoudhury, A.N., Myneni, S.C.B., 2014. Ubiquitous Presence of Fe(II) in Aquatic Colloids and Its Association with Organic Carbon. Environmental Science \& Technology Letters.

Weber, K.A., Pollock, J., Cole, K.A., O'Connor, S.M., Achenbach, L.A., Coates, J.D., 2006. Anaerobic Nitrate-Dependent Iron(II) Bio-Oxidation by a Novel Lithoautotrophic Betaproteobacterium, Strain 2002. Applied and Environmental Microbiology 72, 686694.

Wullstein, L.H., Gilmour, C.M., 1966. Non-enzymatic Formation of Nitrogen Gas. Nature 210, 1150-1151.

Zeng, T., Arnold, W.A., Toner, B.M., 2013. Microscale Characterization of Sulfur Speciation in Lake Sediments. Environmental Science \& Technology 47, 1287-1296.

Zika, R.G., Saltzman, E.S., Cooper, W.J., 1985. Hydrogen-Peroxide Concentrations in the Peru Upwelling Area. Marine Chemistry 17, 265-275. 

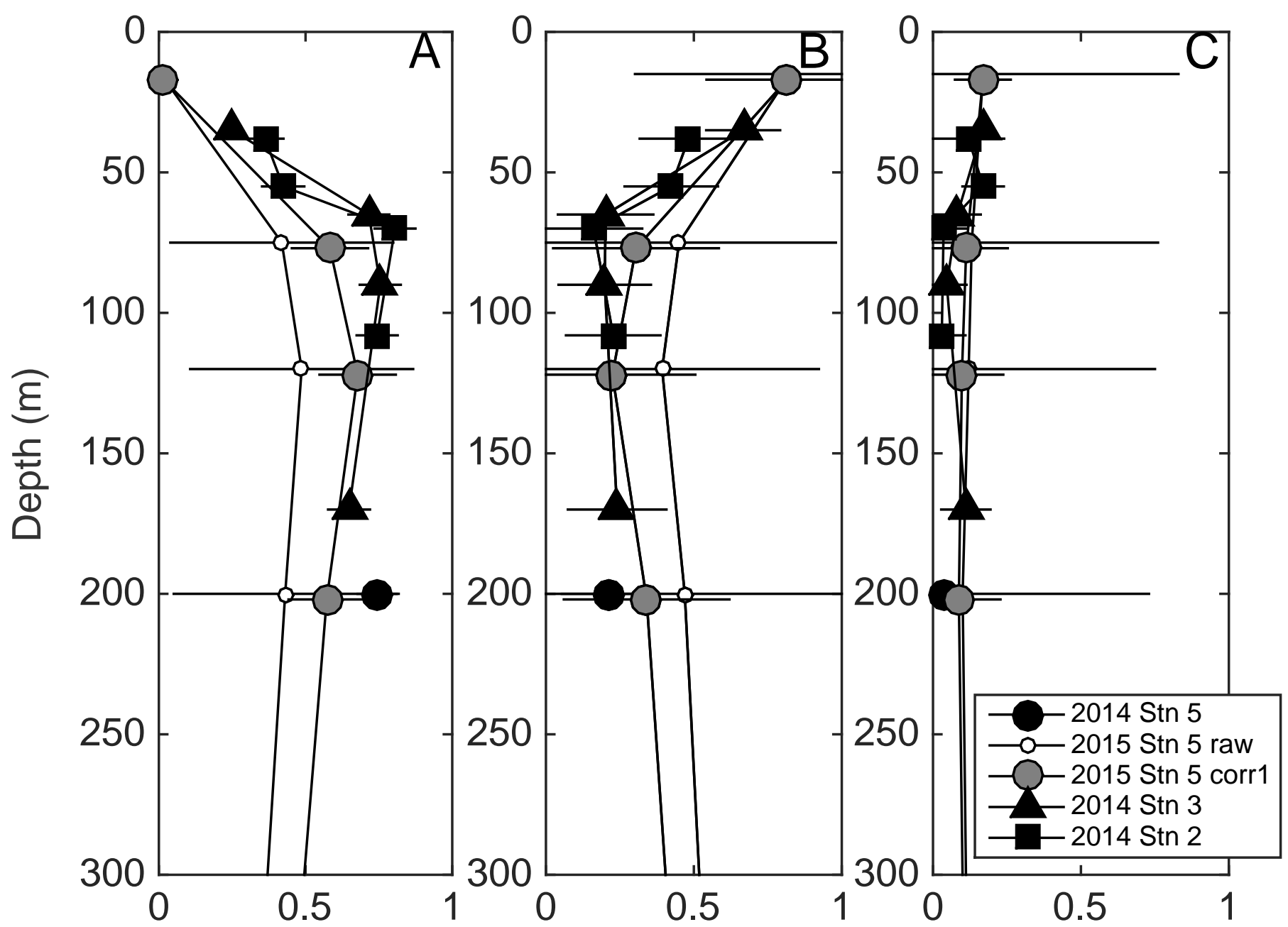

Fraction pFe(III)

Fraction $\mathrm{pFe}(\mathrm{II})$

Fraction pFe-sulfide 


\section{Figure}
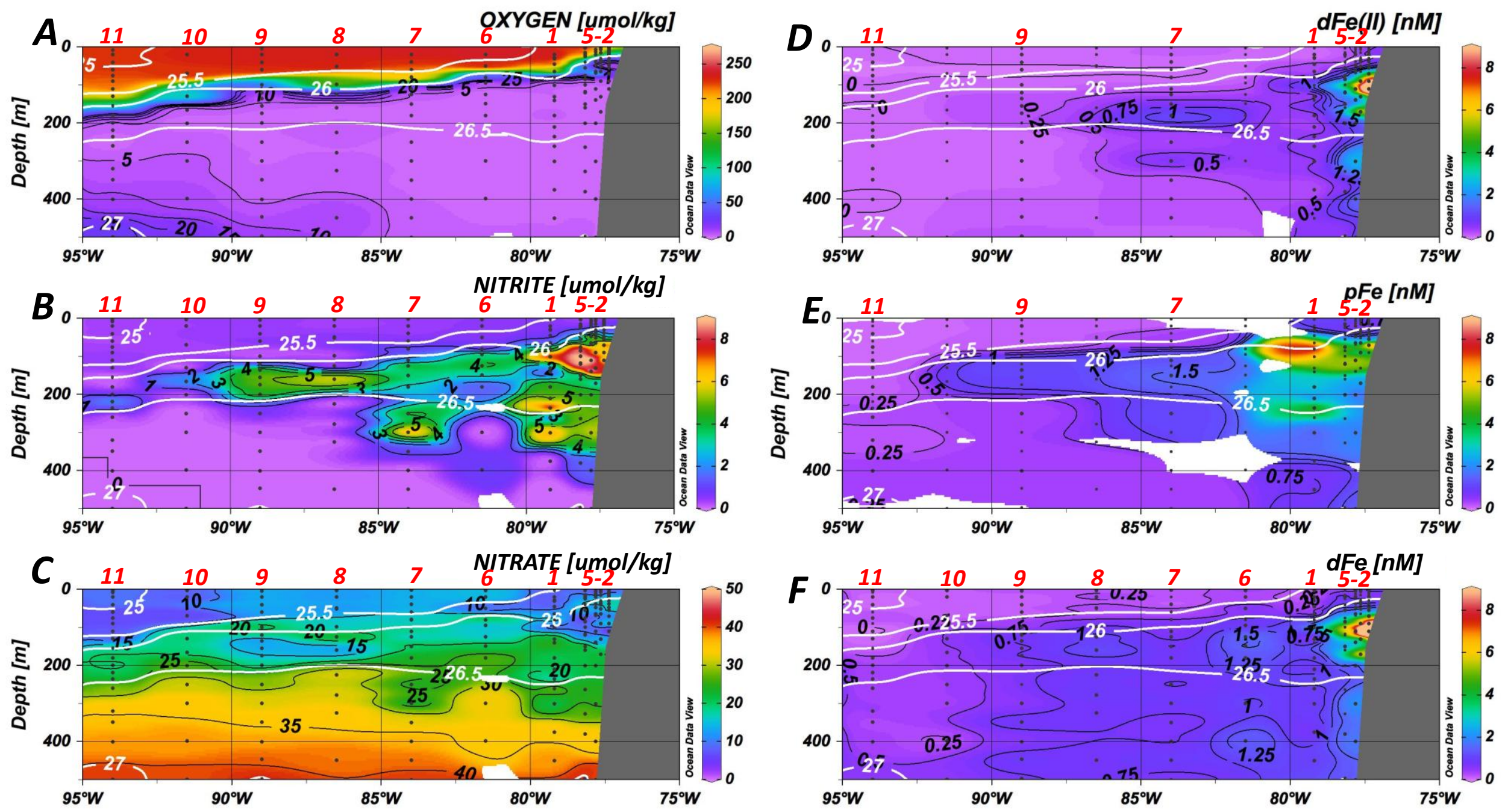
Station 5

$15 \mathrm{~m}$

-

\section{$75 \mathrm{~m}$}
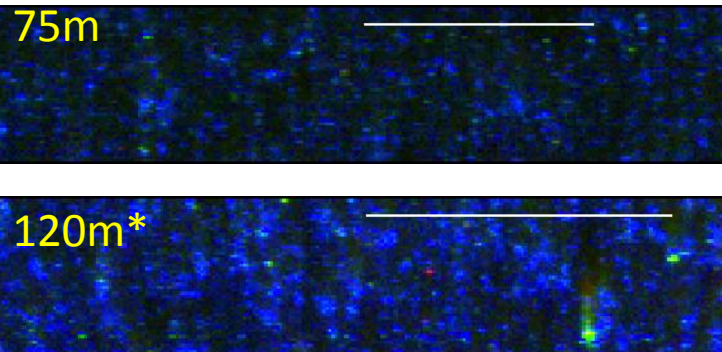

$200 \mathrm{~m}--201409$

$--201510$
Station 3

Station 2

\section{$15 \mathrm{~m}$}

$35 m$

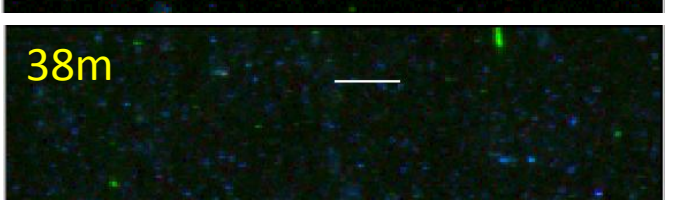

$55 \mathrm{~m}$

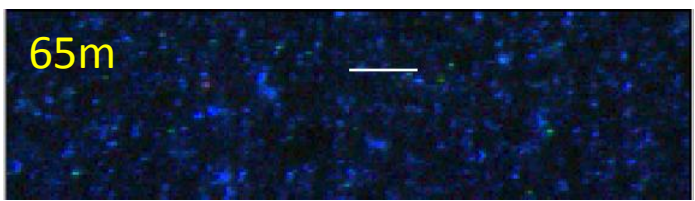

$90 m^{*}$

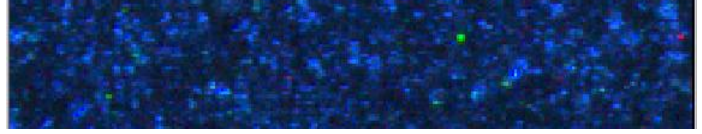

$108 \mathrm{~m}$

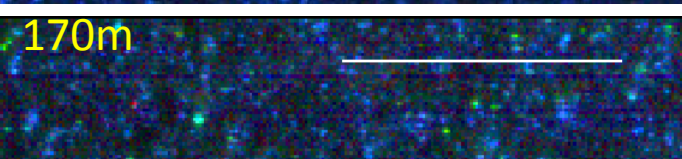

Fe(III) Fe(III) FeSulfide
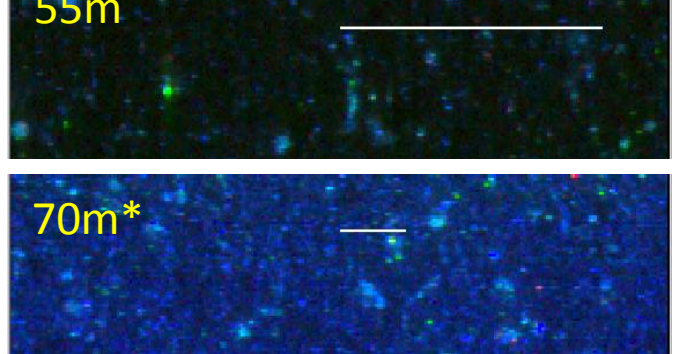

(20)

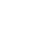




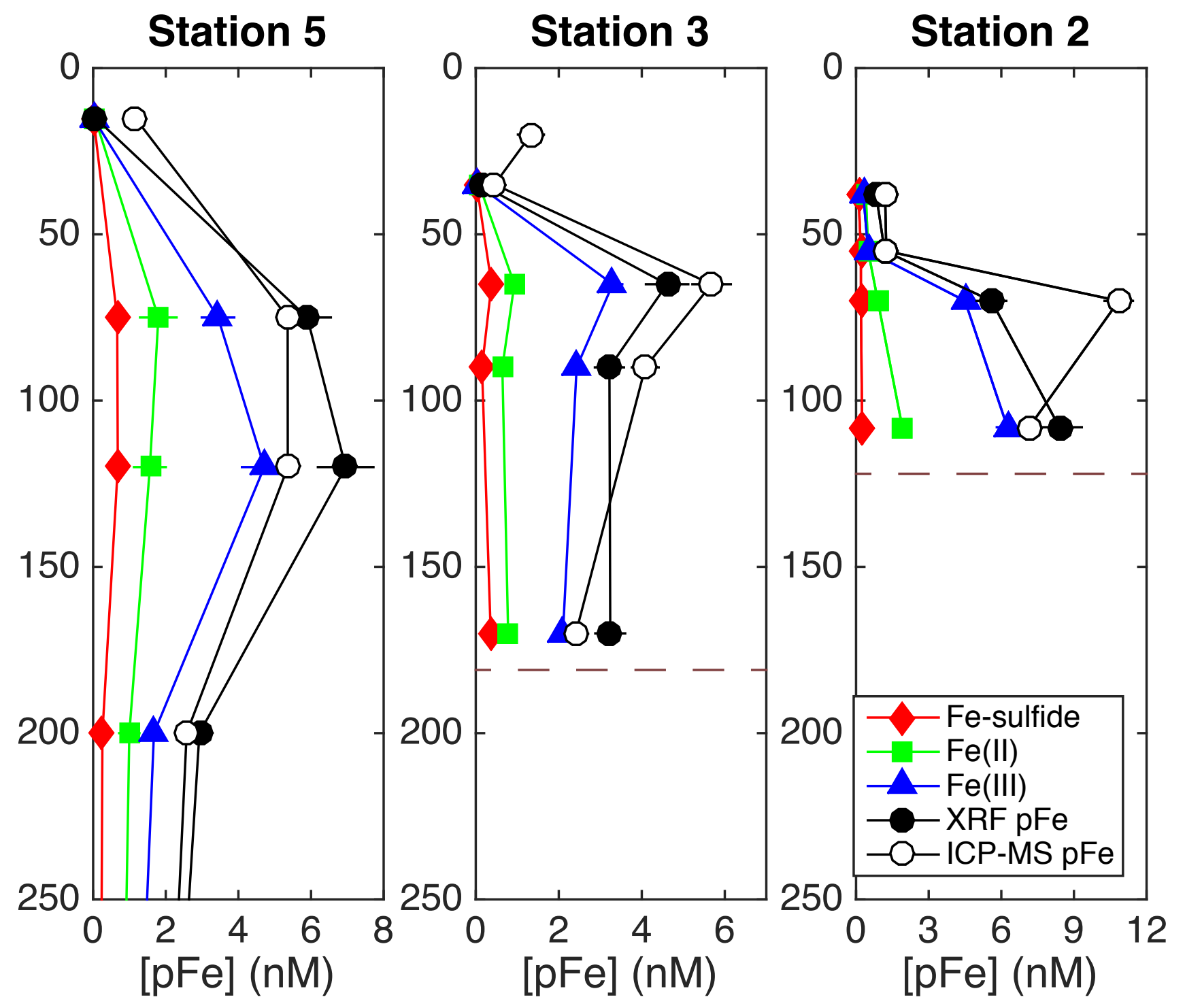




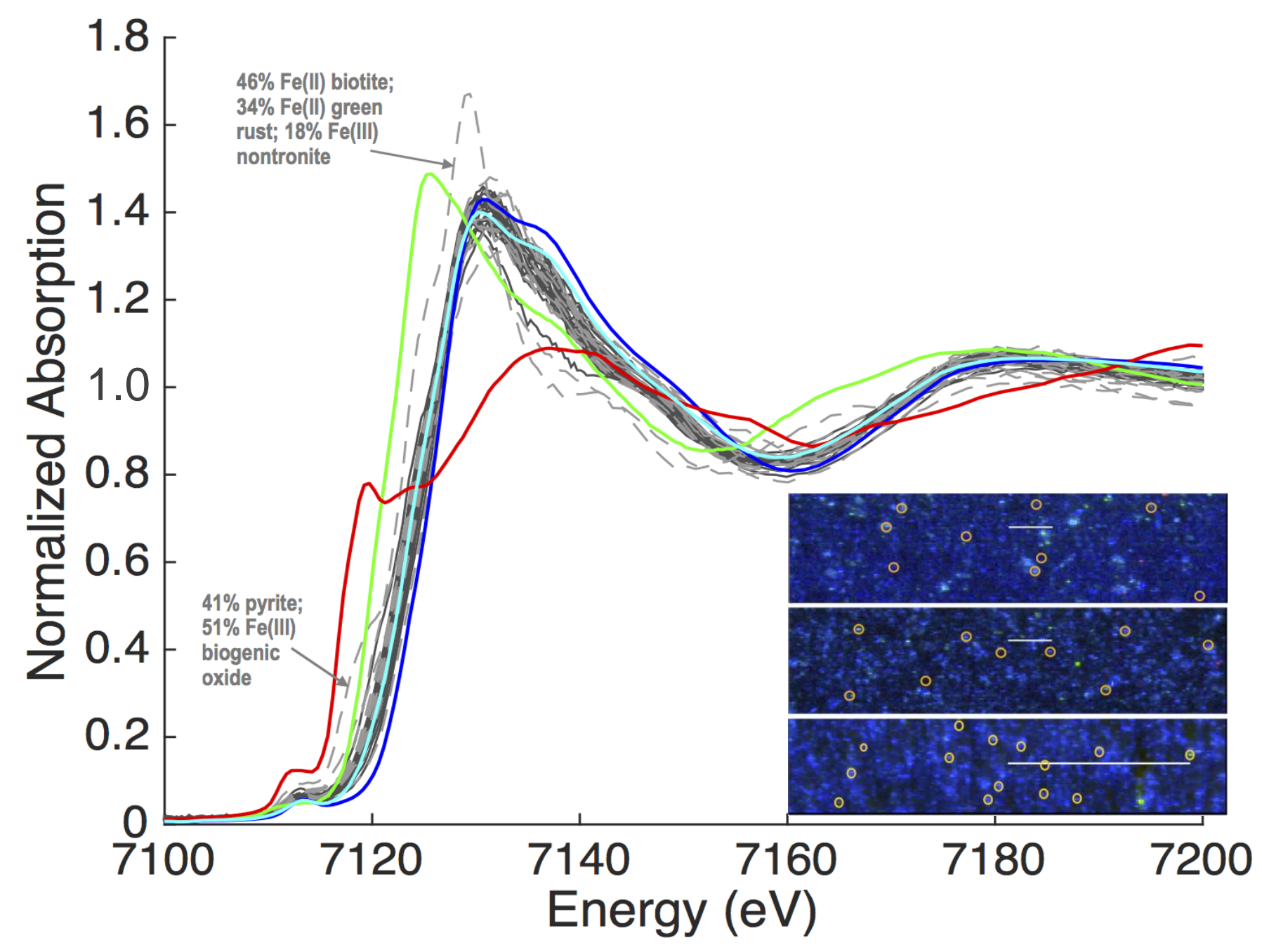


EPZT Stn5 200m EXAFS

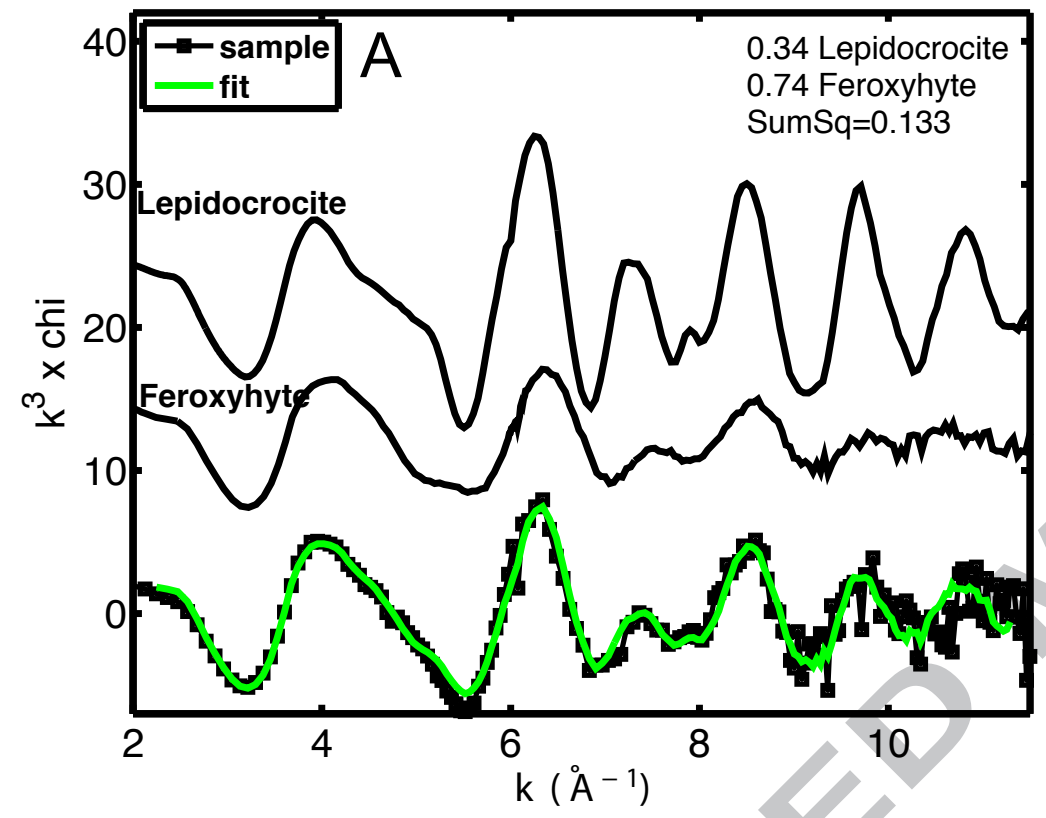

EPZT Stn2 108m EXAFS

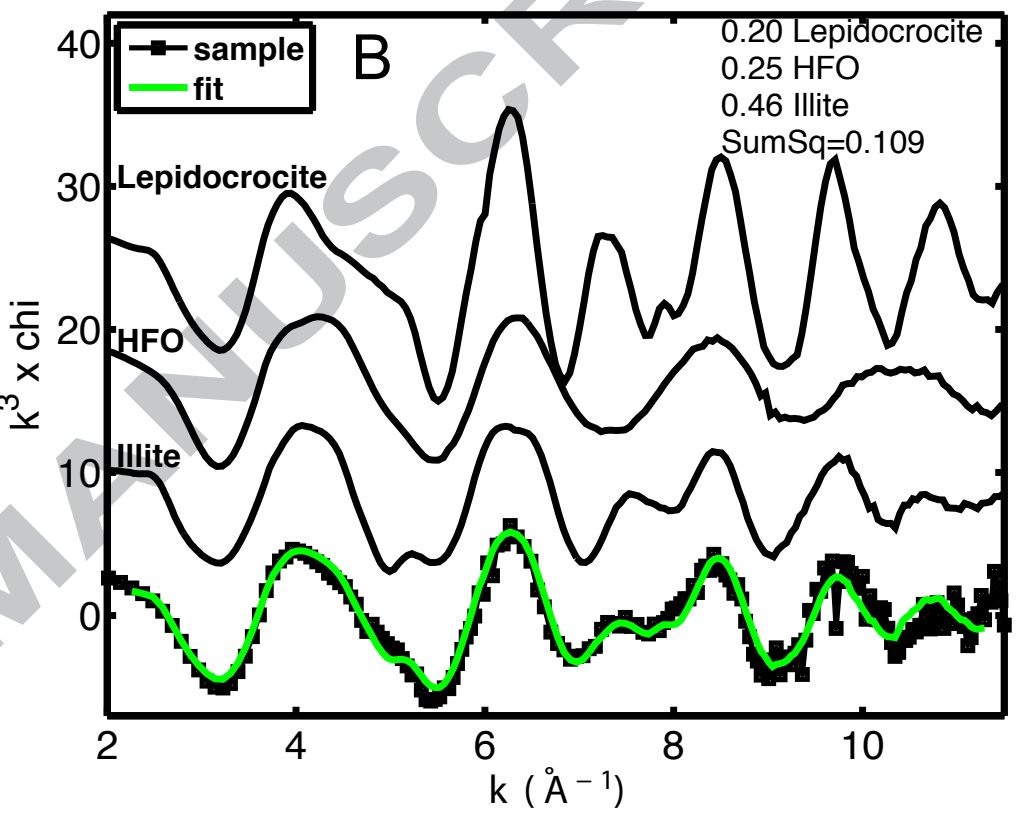




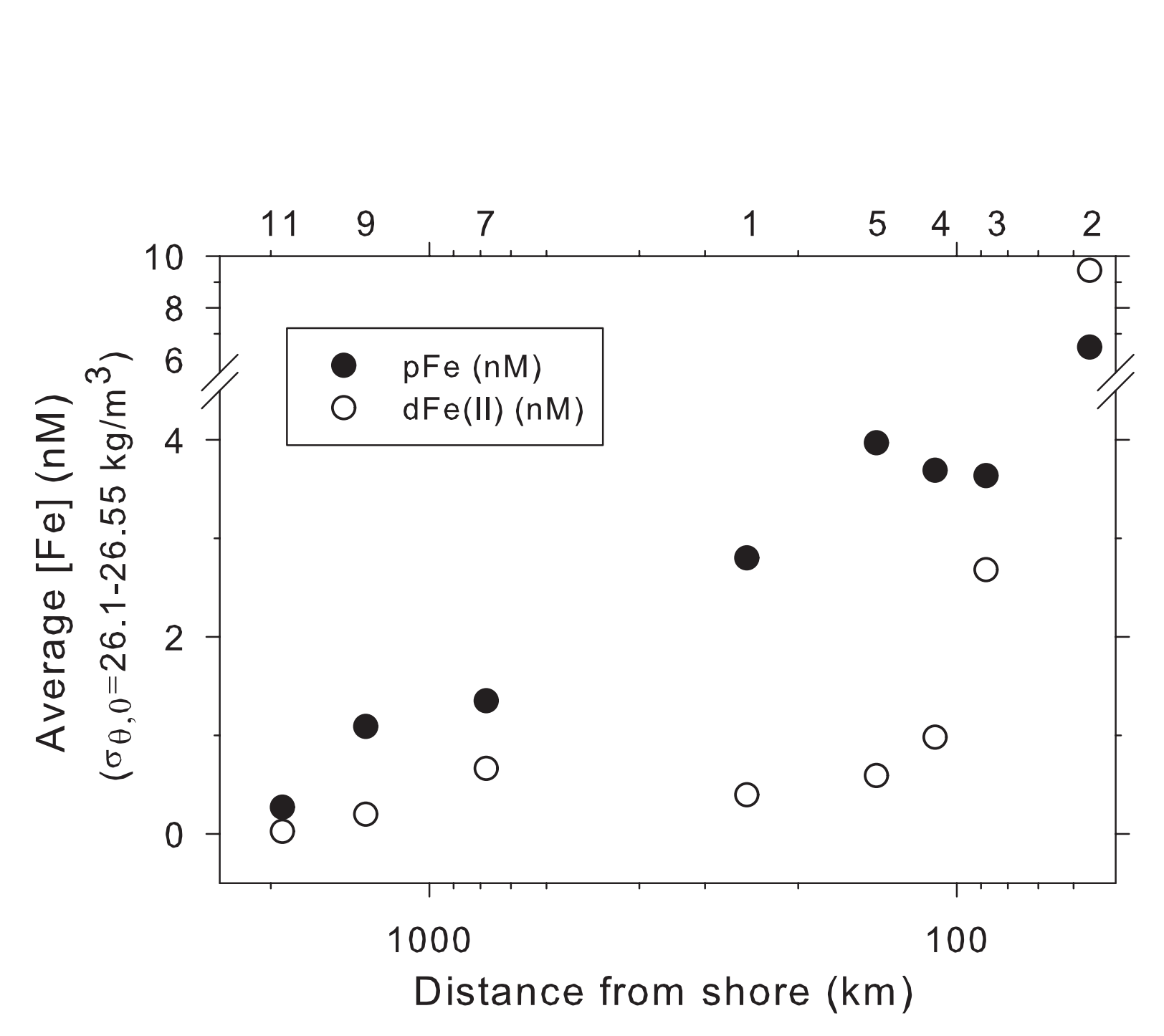

Figure

\section{Figure}

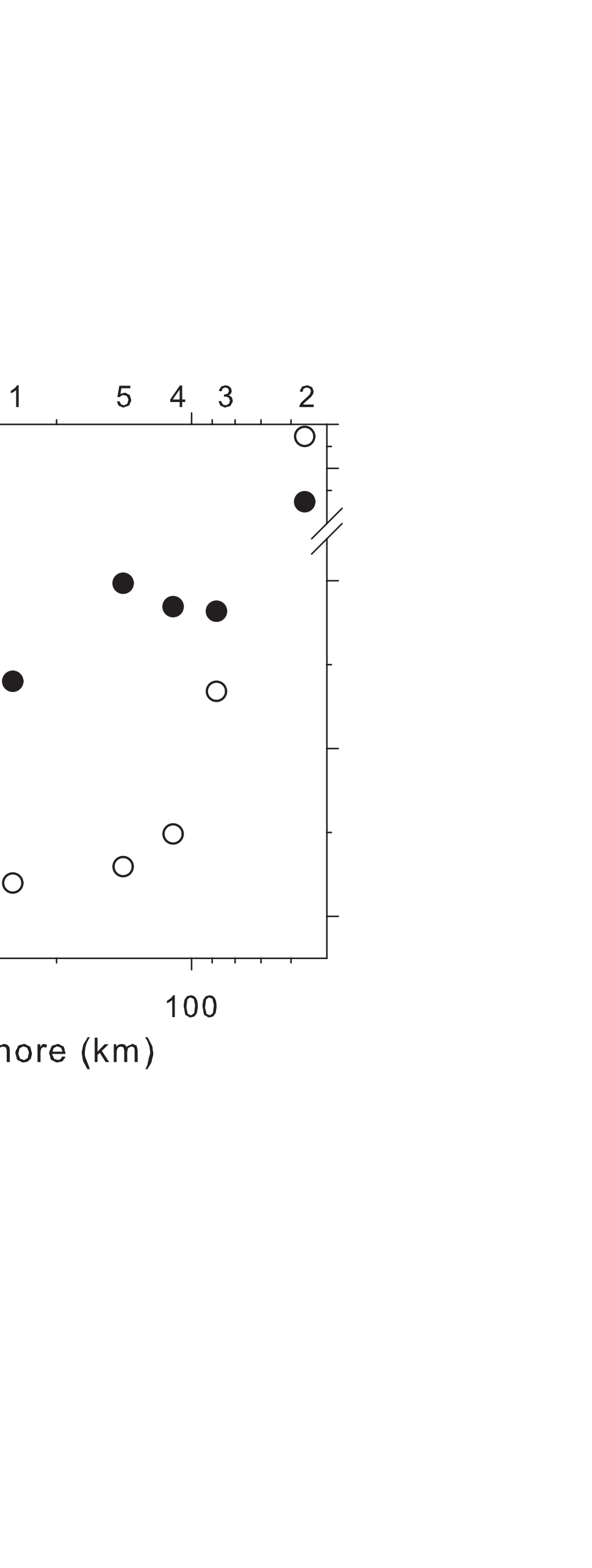




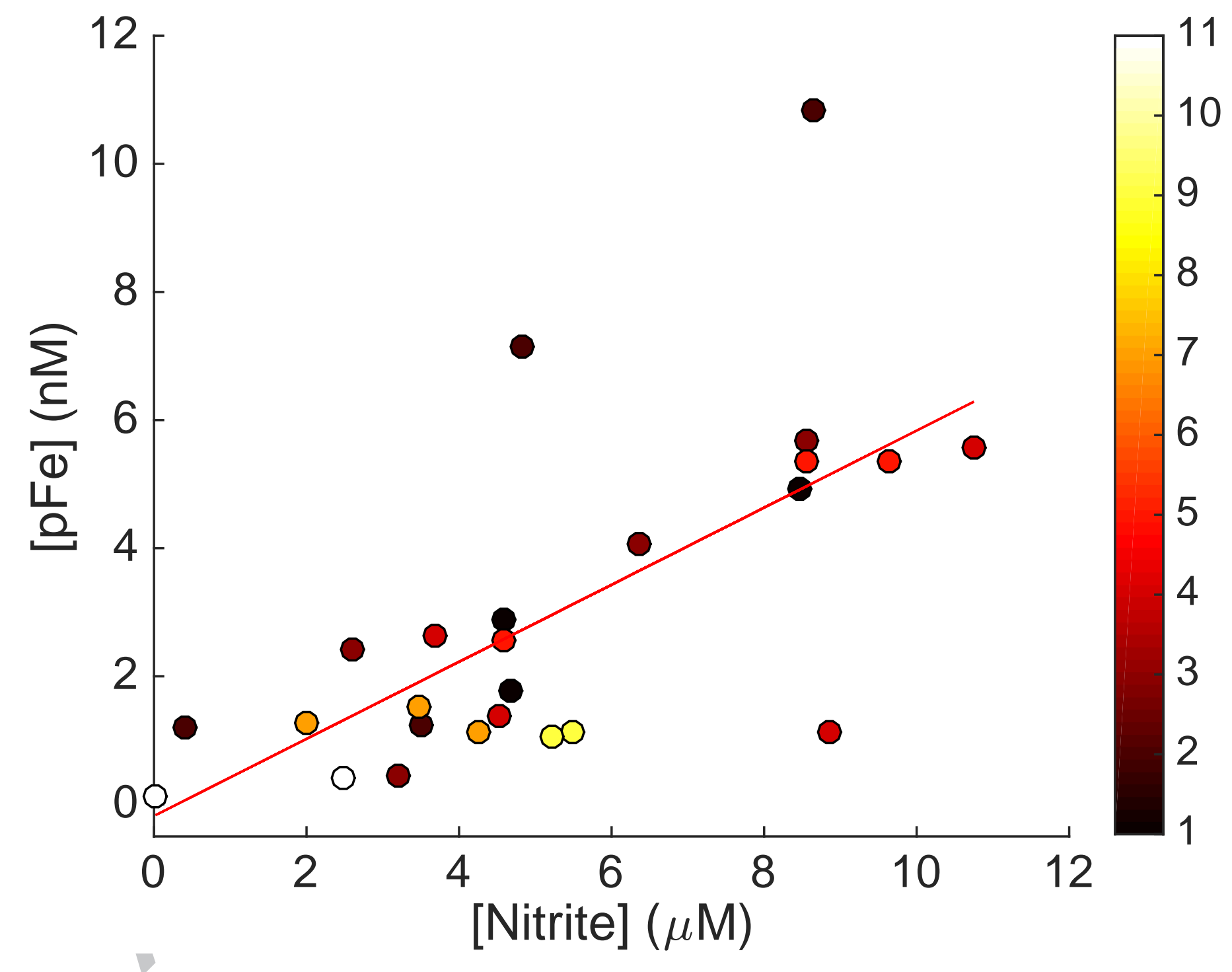




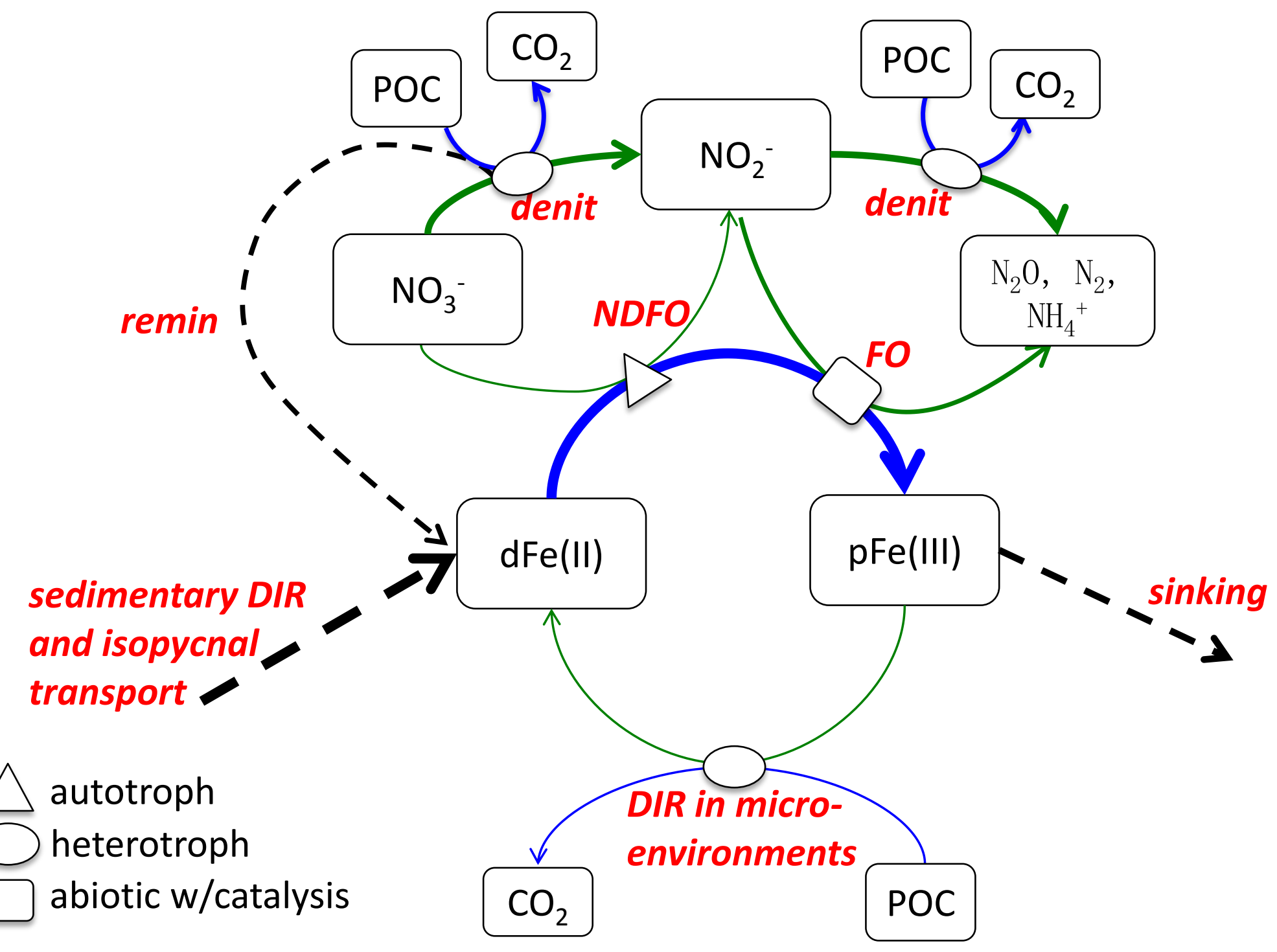

